\title{
Application of the thermal time model for different Typha domingensis populations
}

\author{
Fanny Mabel Carhuancho León ${ }^{1 *} \mathbb{D}$, Pedro Luis Aguado Cortijo ${ }^{1}$, María del Carmen Morató Izquierdo ${ }^{2}$ and
} María Teresa Castellanos Moncho²

\begin{abstract}
Background: Cattail (Typha domingensis Pers.) is a perennial emergent plant which is used in Green Floating Filters (GFFs), one of the most innovative systems of wastewater treatment to bioremediate eutrophic waters and produce biomass as biofuel feedstocks. The establishment of cattails in GFFs depends on the seed germination and plant responses under conditions of a new habitat. This study analysed the germination responses of four different populations of cattails through a thermal time model to know their basic parameters of germination and which population would be more adapted to the conditions tested.
\end{abstract}

Results: Seeds from the Badajoz (Ba), Cuenca (Cu), Madrid (Ma), Seville (Se) and Toledo (To) populations were exposed to different thermal regimes (constant, and alternating temperatures between 15 and $30^{\circ} \mathrm{C}$ ) and different darkness treatments (between 0 and 20 days with $24 \mathrm{~h}$ dark photoperiod, then exposed to light with $12 \mathrm{~h}$ light/dark photoperiod) to determine the parameters of the thermal model from germination levels in each treatment. To population was used to validate the thermal time parameters of other populations. Regardless of the other parameters, no germination occurred in total darkness. The mean value of base temperature $\left(T_{b}\right)$ was $16.4 \pm 0.2^{\circ} \mathrm{C}$ in all treatments. Optimum temperature $\left(T_{0}\right)$ values in $\mathrm{Ma}$ and $\mathrm{Ba}$ were $25^{\circ} \mathrm{C}$, and those in $\mathrm{Cu}$ and $\mathrm{Se}$ were $22.5^{\circ} \mathrm{C}$. The germination response decreased when the temperature approached $T_{b}$ and increased when it was close to $T_{0}$. In comparison to alternating temperatures, constant temperatures had the highest germination response and lowest thermal time $\left(\theta_{T}(50)\right)$. Darkness treatments had a direct relationship with $\theta_{T}(50)$. The population origin also affected seed germination; $\mathrm{Cu}$ had the highest values of $\mathrm{T}_{\mathrm{O}}$ and germination response but had a lower $\theta_{T}(50)$, which coincides with the lowest mean ambient temperatures.

Conclusion: According to these results, the germination response of cattails was high in all populations under optimal conditions but was affected to a greater or lesser extent depending on thermal regimes, darkness treatments, and populations. The thermal time model allowed us to determine that $T_{0}$ was between 22.5$25^{\circ} \mathrm{C}$ and that $\mathrm{Cu}$ is the best population regarding the germination response under the conditions tested.

Keywords: Typha domingensis, Thermal time, Seed germination, Green floating filter

\footnotetext{
* Correspondence: mabel.carhuancho.leon@alumnos.upm.es

${ }^{1}$ Agroenergy Research Group, Department of Agricultural Production. School of Agricultural, Food and Biosystems Engineering, Universidad Politecnica de Madrid (UPM), Avenue Complutense s/n, 28040 Madrid, Spain

Full list of author information is available at the end of the article
}

(C) The Author(s). 2020 Open Access This article is licensed under a Creative Commons Attribution 4.0 International License, which permits use, sharing, adaptation, distribution and reproduction in any medium or format, as long as you give appropriate credit to the original author(s) and the source, provide a link to the Creative Commons licence, and indicate if changes were made. The images or other third party material in this article are included in the article's Creative Commons licence, unless indicated otherwise in a credit line to the material. If material is not included in the article's Creative Commons licence and your intended use is not permitted by statutory regulation or exceeds the permitted use, you will need to obtain permission directly from the copyright holder. To view a copy of this licence, visit http://creativecommons.org/licenses/by/4.0/ The Creative Commons Public Domain Dedication waiver (http://creativecommons.org/publicdomain/zero/1.0/) applies to the data made available in this article, unless otherwise stated in a credit line to the data. 


\section{Background}

Typha is a perennial monocotyledon plant genus that is widely distributed [1] mainly in wetlands, marshlands and other aquatic habitats. Typha domingensis Pers. (commonly known as "cattail") is a species of this genus, with an annual growth cycle, that is widely distributed around the world [1]. It is a warm temperate and pantropical species [2]. This species is also often found in the Iberian Peninsula and the Balearic Islands [3]. The reproduction of this species occurs by vegetative spread (rhizomes) and from seed $[4,5]$. Seed production is very high due to a single female spadix that can produce more than 600,000 small single-seeded fruits [1]. Although considered an invasive plant, cattail provides different raw materials (for weaving) and the rhizomes serve as food for humans and livestock. In recent years, cattail has been used in wastewater treatments and reclamation of industrial sites due to its great capacity to remove particle matter, nutrients and metals from eutrophic waters [6-8]. For wastewater treatment, this species has been used to form green filters that use different types of biological elements (plants and microorganisms). Among the numerous existing green-filter systems, the innovative systems specially designed for small urban agglomerations are called green floating filters (GFFs) [9]. Different Typha species have been used in GFFs, but T. domingensis presents an advantage compared to other species: it has the capacity to produce more biomass in deeper water $[10,11]$ and to quickly form a floating and filtering plant mat that improves the purification of wastewater in a GFF [12]. Different studies have demonstrated that managed cattail in constructed wetlands could provide beneficial ecosystem services [6, 7] and sustainable biomass for biofuel feedstocks $[13,14]$ and bioproducts [15].

Seed germination is an important biological process in plants. The success or failure of introducing a population into a new local habitat is closely related to its seed germination ability. The dynamics of this process are complex and influenced by genetic changes and/or phenotypic variability in the different plant populations $[16,17]$. An example of this complexity is the dormancy mechanism. It is an internal condition of seeds that impedes its germination under otherwise adequate hydric, thermal and gaseous conditions [18, 19]. This mechanism is very rare in seed crops but common in weed populations and is associated with weed dispersibility [20]. Dormancy can be ended by one or more environmental factors, such as temperature, water potential, light, and soil $\mathrm{pH}$. However, different dormancy behaviours are related to environmental factors during seed development [19] and seeds can incorporate the effects of these factors over time [21].
In the case of cattail, germination studies have focused on avoiding its propensity to invade natural ecosystems and cause negative impacts. Previous studies have demonstrated that environmental requirements, such as temperature, light, depth of water, salinity, $\mathrm{pH}$, and $\mathrm{O}_{2}$ concentration could influence the seed germination of different species of Typha [5, 16, 22-24].

One of the main factors required for seed germination is the temperature [25]. This factor has the greatest effect on dormancy, and on the germination rate in the case of seeds that do not exhibit dormancy [26], and many studies have been implemented using constant temperatures [17, $27,28]$ or/and alternating temperatures $[29,30]$ on seed germination. Light is another environmental factor that is important for releasing seeds from dormancy $[25,31]$. Among the environmental requirements related specifically to cattail seed germination, one of the main factors is humidity. Germination of cattail seeds only occurs in wet or flooded environments [5, 32, 33] at low soil water potentials $<1 \mathrm{MPa}$ [34].

Genetic determinants also influence the germination of cattail seeds $[35,36]$. Sometimes, the origins of populations determine the germination conditions of the seeds regardless of whether they are of the same species $[24,37]$. Moreover, the factors that determine the germination of the mother plant (temperature, light, humidity, and others) must be taken into account [38]. Knowledge of the cattail populations germination capacity can help in the establishment in GFFs or the control of its expansion in different places [39].

There are various tools for the study of seed germination. In recent years, population-based threshold models have been widely used in germination studies. There are two types of models: empirical and mechanistic. The first is used for a specific objective, but the results are more difficult to apply [40, 41]. Mechanistic models, on the other hand, are based on known and experimentally quantified the environmental effects on seed dormancy, imbibition, and germination [41]. These models have been applied, therefore, to explain the most successful seed germination in recent years [29, 42, 43]. The main models developed are the thermal time model, the hydrotime model, and the hydrothermal model, which describe the effects of temperature and/or water potential on the germination rate by applying a linear relationship [42, 44, 45]. These models use biological time, which can be quantified by the extent to which water potential and/or temperature of each seed exceeds thresholds (base), below which germination is not completed [20]. The hydrotime model describes the response germination of seed populations in response to change in water potentials. The thermal time model is based on response germination under variable temperature regimes, and the hydrothermal model is the integration of 


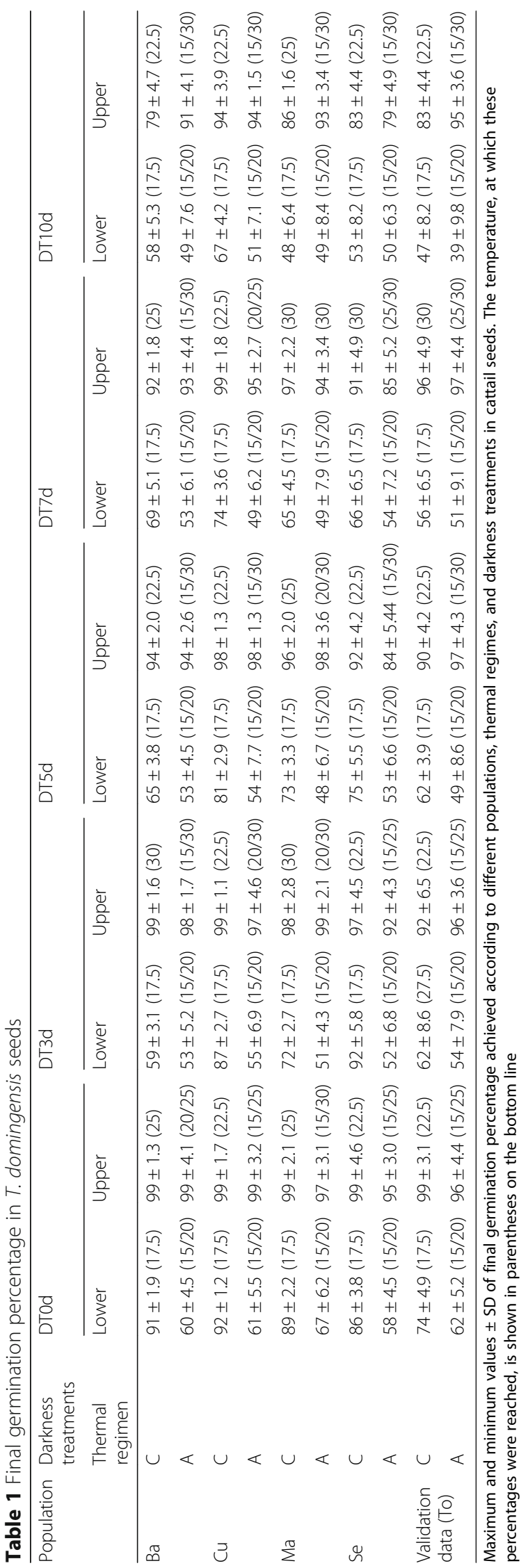


Table 2 Multifactor analysis of variance and multiple range tests for different populations, darkness treatments and thermal regimes

\begin{tabular}{|c|c|c|c|c|c|c|c|c|c|c|c|}
\hline \multicolumn{3}{|c|}{ Multifactorial ANOVA } & \multicolumn{9}{|c|}{ Multiple Ranges test } \\
\hline Factors & $\mathrm{Fd}$ & $\mathrm{F}$ & Po & $n$ & GR \% & DT & $\mathrm{N}$ & GR \% & $\mathrm{Tr}$ & $n$ & GR\% \\
\hline Po & 3 & $22.66^{* * *}$ & $\mathrm{Ba}$ & 60 & $82.2^{b}$ & DTOd & 48 & $91.4^{a}$ & 17.5_0 & 20 & $74.0^{d}$ \\
\hline DT & 4 & $30.77^{* * *}$ & $\mathrm{Cu}$ & 60 & $88.2^{\mathrm{a}}$ & DT3d & 48 & $87.6^{\mathrm{b}}$ & $17.5 \_5$ & 20 & $54.0^{e}$ \\
\hline $\mathrm{Tr}$ & 5 & $51.45^{* * *}$ & $\mathrm{Ma}$ & 60 & $85.9^{\mathrm{a}}$ & DT5d & 48 & $82.3^{c}$ & 20.0_0 & 20 & $83.0^{\mathrm{bc}}$ \\
\hline PoxDT & 12 & 0.08 & $\mathrm{Se}$ & 60 & $76.6^{c}$ & DT7d & 48 & $79.9^{c}$ & 20.0_10 & 20 & $82.0^{\mathrm{bc}}$ \\
\hline PoxTr & 9 & 0.68 & & & & DT10d & 48 & $75.1^{d}$ & 22.5_0 & 20 & $92.0^{\mathrm{a}}$ \\
\hline DTxTr & 12 & 0.73 & & & & & & & 22.5 & 20 & $89.0^{a b}$ \\
\hline \multirow[t]{6}{*}{ PoxDTxTr } & 36 & 0.15 & & & & & & & $22.5 \_15$ & 20 & $93.0^{\mathrm{a}}$ \\
\hline & & & & & & & & & 25.0_0 & 20 & $92.0^{\mathrm{a}}$ \\
\hline & & & & & & & & & 25.0_10 & 20 & $87.0^{a b c}$ \\
\hline & & & & & & & & & 27.5_0 & 20 & $88.0^{\mathrm{abc}}$ \\
\hline & & & & & & & & & $27.5 \_5$ & 20 & $82.0^{c}$ \\
\hline & & & & & & & & & 30.0_0 & 20 & $88.0^{\mathrm{abc}}$ \\
\hline
\end{tabular}

Po Populations; DT Darkness treatments; $\operatorname{Tr}$ Thermal Regimes $\left(\mathrm{T}_{\mathrm{m} \_} \Delta \mathrm{T}\right)$

Significant codes: ${ }^{* *} 0.001,{ }^{* *} 0.01,{ }^{*} 0.05$. Different letters represent statistically significant differences between treatment of each population according to LSD test $(p<0,05)$

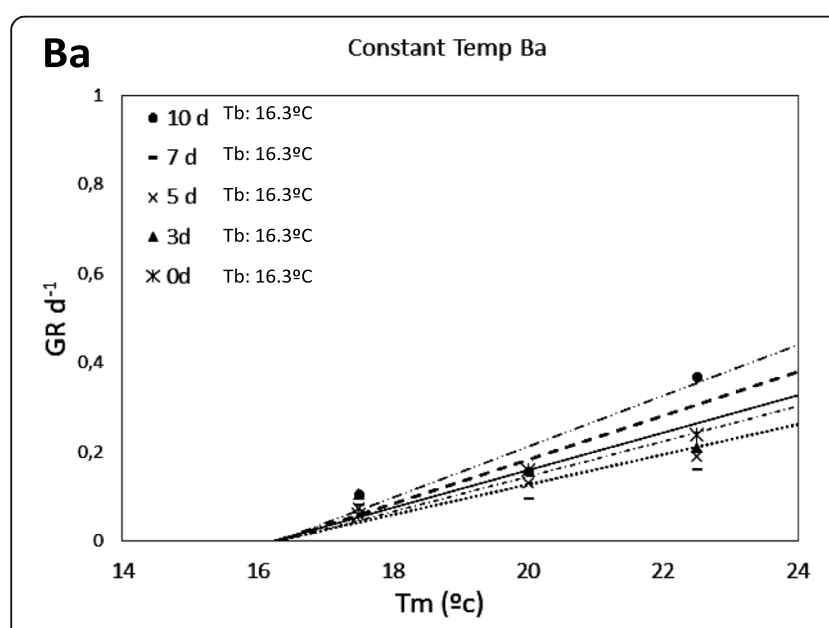

Ma

Constant Temp Ma
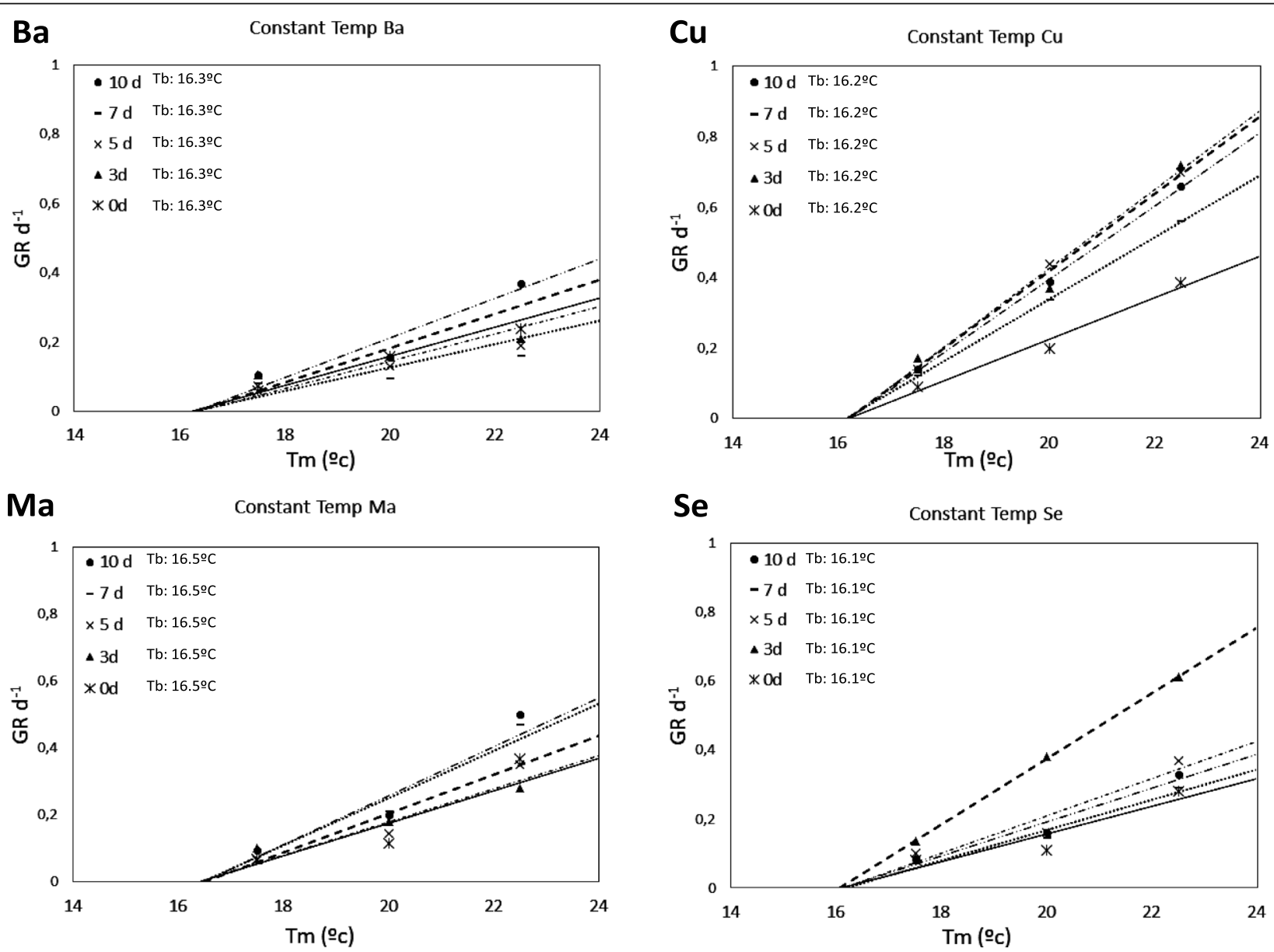

Se

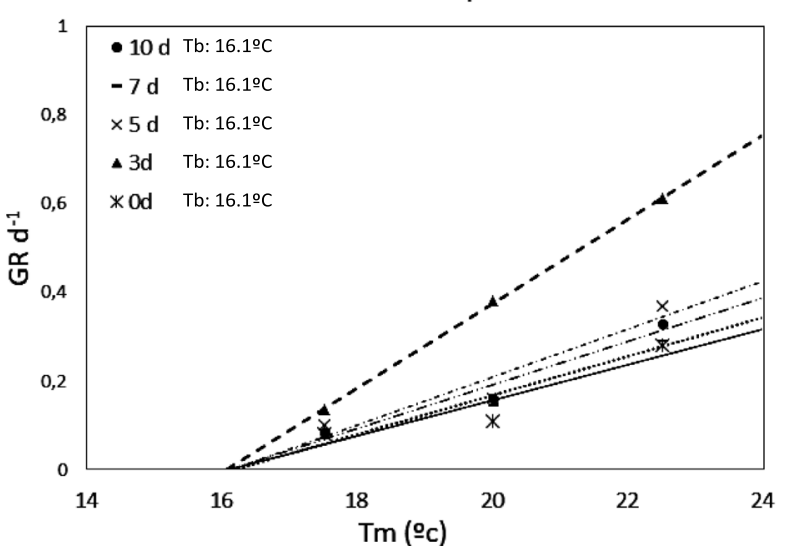

Fig. 1 Relationship between $G R_{(50)}$ and $T_{m}$ of cattail seeds from different populations with $\Delta T=0{ }^{\circ} \mathrm{C}$ and different darkness treatments 
both temperature and water potential [25, 42, 44]. The use of these models could provide a way to link ecological observation of germination to laboratory studies [20].

The thermal time model allows for the estimation of the width of the thermal range over which seeds of a particular species can germinate. This thermal range can be described by the three cardinal temperatures: optimum temperature $\left(\mathrm{T}_{\mathrm{o}}\right)$, base temperature $\left(\mathrm{T}_{\mathrm{b}}\right)$, and ceiling temperature $\left(\mathrm{T}_{\mathrm{c}}\right)$ [19]. $\mathrm{T}_{\mathrm{o}}$ is the temperature at which germination is most rapid, while $T_{b}$ and $T_{c}$ are the lowest and highest temperatures at which germination can occur, respectively [25]. Also, the dormancy status of the seeds can influence the thermal range between $T_{b}$ and $T_{c}$ [25]. This model is based on mathematical parameters, such as thermal time $\left(\theta_{T}\right.$, degree-day/ degree-hour), the three cardinal temperatures $\left(\mathrm{T}_{\mathrm{b}}, \mathrm{T}_{\mathrm{o}}\right.$ and $\left.\mathrm{T}_{\mathrm{c}},{ }^{\circ} \mathrm{C}\right)$, the mean temperature of incubation $\left(\mathrm{T}_{\mathrm{m}}\right.$, $\left.{ }^{\circ} \mathrm{C}\right)$, the germination rate (GR) and the time to germination $(\mathrm{t})$ for a specific germination percentile $(\mathrm{g})$. The $\theta_{T}$ is the daily differences between prevailing temperature and $T_{b}$, which are accumulated to complete germination
[30]. GR is considered as the inverse of time to germination for specific germination percentages; moreover, it increases with increasing temperature between $\mathrm{T}_{\mathrm{b}}$ and $T_{o}$, while it decreases between $T_{o}$ and $T_{c}$ [19]. The thermal time model has been used successfully to predict the occurrence of seed germination under non-waterlimiting conditions, thus explaining approximately $80 \%$ of the variation in the cumulative percentile [46].

The aims of this work, therefore, was to determine the ecophysiological parameters of seeds germination for different populations of $T$. domingensis from $\mathrm{Ba}$ dajoz $(\mathrm{Ba})$, Cuenca $(\mathrm{Cu})$, Madrid $(\mathrm{Ma})$ and Seville $(\mathrm{Se})$ using thermal time model. These parameters allow us to know the germination behaviour of each population and the influence of environmental parameters, such as level and amplitude of temperatures or light exposure, on its germination responses. This analysis can be useful to know which would be the best population for establishing in a new habitat as well as assessing its ability to expand as a weed in a future scenario with warmer temperatures in the Mediterranean zone because of climate change.
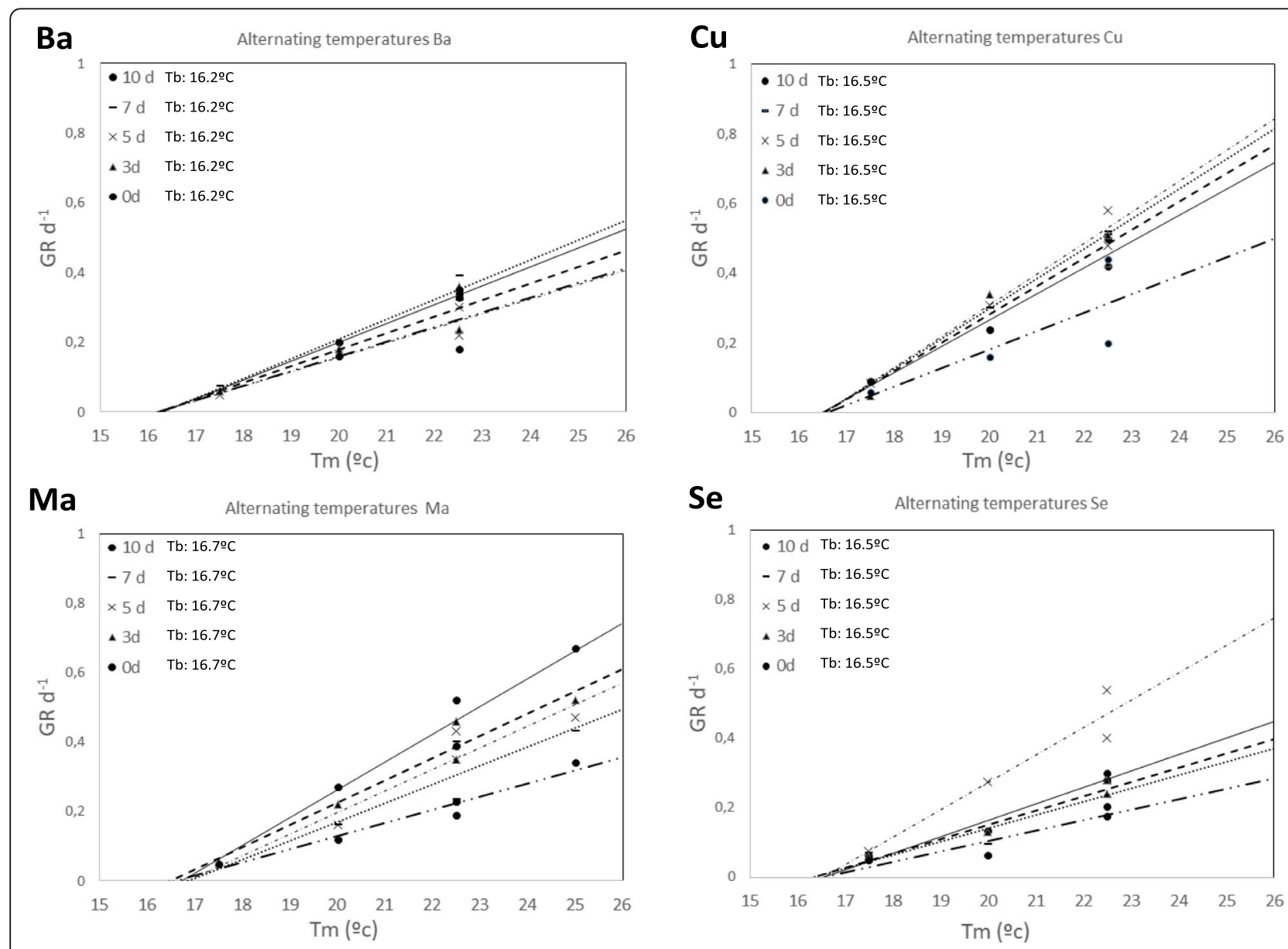

Se

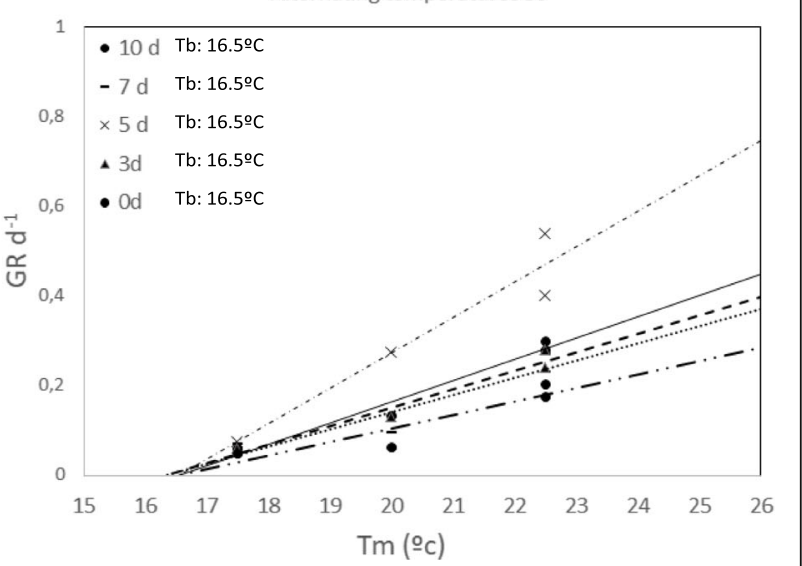

Fig. 2 Relationship between $G R_{(50)}$ and $T_{m}$ of cattail seeds from different populations with $\Delta T \geq 0{ }^{\circ} \mathrm{C}$ and different darkness treatments 


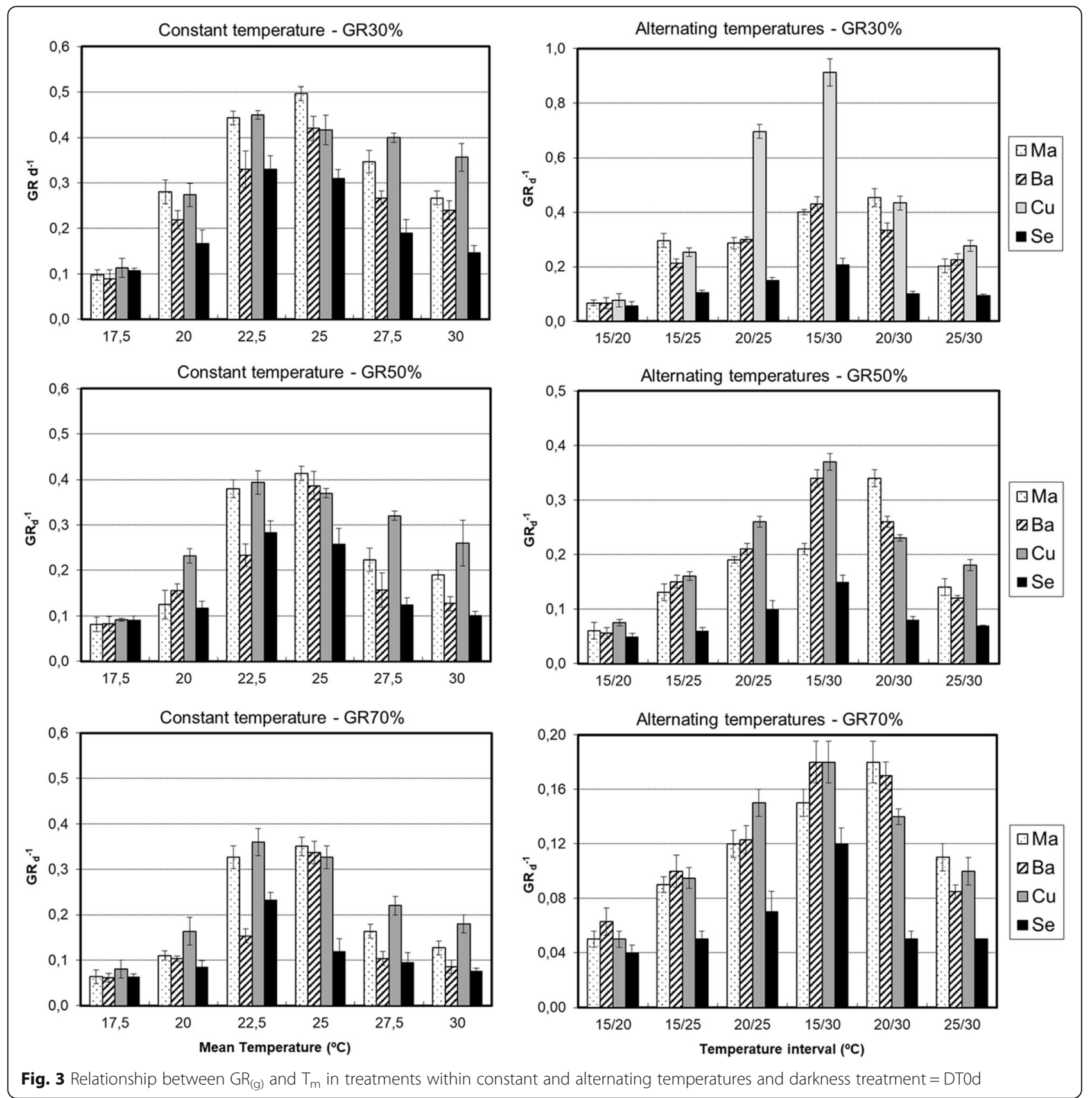

\section{Results}

\section{Final germination responses in the different treatments}

Table 1 shows the germination responses achieved in each treatment. To simplify Table 1, the germination responses to each set of temperatures and darkness treatments within the same population were summarized, and these are shown as lower and upper germination responses for constant (C) and alternating (A) thermal regimes.

The results of the multifactor analysis of variance carried out with the data mentioned above are shown in Table 2. There were significant differences among the populations (Po), darkness treatments (DT) and thermal regimes $(\mathrm{Tr})$ when each of these factors was analyzed separately at $p<0.05$; however, the interaction between the two factors (PoxDP, DPxTr, PoxTr) and among the three factors (PoxDPxTr) was not significant (Table 2).

No germination was obtained in DT20d treatment (20 days with $24 \mathrm{~h}$ darkness photoperiod), so the data from these treatments have not been included in the study. These results suggest that the dormancy of cattail seeds was not interrupted independently of thermal treatment or population. In others darkness treatments, different germination responses were reached according to the 
Table 3 Parameters of the thermal models for cattail seeds with constant (A) and alternating (B) temperatures

\begin{tabular}{|c|c|c|c|c|c|c|c|c|c|c|c|c|c|}
\hline \multicolumn{7}{|c|}{ A. Thermal regimes with constant temperatures } & \multicolumn{7}{|c|}{ B. Thermal regimes with alternating temperatures } \\
\hline Code & $\begin{array}{l}\mathrm{T}_{\mathrm{b}} \\
{ }^{\circ} \mathrm{C}\end{array}$ & $\begin{array}{l}\mathrm{T}_{\mathrm{O}} \\
{ }^{\circ} \mathrm{C}\end{array}$ & $\begin{array}{l}\log \left(\theta_{T}(50)\right) \\
\left(\log ^{\circ} \mathrm{d}\right)\end{array}$ & $\begin{array}{l}\mathrm{o}^{\circ} \theta_{\mathrm{T}} \\
\left(\log ^{\circ} \mathrm{d}\right)\end{array}$ & $\begin{array}{l}\theta_{\mathrm{T}}(50) \\
\left({ }^{\circ} \mathrm{d}\right)\end{array}$ & $\begin{array}{l}\theta_{\mathrm{T}}(50) \\
\left({ }^{\circ} \mathrm{h}\right)\end{array}$ & Code & $\begin{array}{l}\mathrm{T}_{\mathrm{b}} \\
{ }^{\circ} \mathrm{C}\end{array}$ & $\begin{array}{l}\mathrm{T}_{0} \\
{ }^{\circ} \mathrm{C}\end{array}$ & $\begin{array}{l}\log \left(\theta_{\mathrm{T}}(50)\right) \\
\left(\log ^{\circ} \mathrm{d}\right)\end{array}$ & $\begin{array}{l}\circ \theta \top \mathrm{T} \\
\left(\log ^{\circ} \mathrm{d}\right)\end{array}$ & $\begin{array}{l}\theta_{T}(50) \\
\left({ }^{\circ} \mathrm{d}\right)\end{array}$ & $\begin{array}{l}\theta_{\mathrm{T}}(50) \\
\left({ }^{\circ} \mathrm{h}\right) \\
\end{array}$ \\
\hline BaCDTOd & $16 \pm 0.3$ & 25 & 2.72 & 0.5 & 15.33 & 368 & BaADT0d & $16 \pm 0.2$ & 22.5 & 2.81 & 0.3 & 16.61 & 399 \\
\hline BaCDT3d & $16 \pm 0.3$ & 25 & 2.81 & 0.5 & 16.61 & 399 & BaADT3d & $16 \pm 0.2$ & 22.5 & 2.94 & 0.3 & 18.02 & 454 \\
\hline $\mathrm{BaCDT5d}$ & $16 \pm 0.3$ & 25 & 2.87 & 0.5 & 17.64 & 423 & BaADT5d & $16 \pm 0.2$ & 22.5 & 3.00 & 0.3 & 20.09 & 482 \\
\hline BaCDT7d & $16 \pm 0.3$ & 25 & 2.96 & 0.5 & 19.21 & 461 & BaADT7d & $16 \pm 0.2$ & 22.5 & 3.06 & 0.3 & 21.33 & 512 \\
\hline BaCDT10d & $16 \pm 0.3$ & 25 & 3.06 & 0.5 & 21.27 & 510 & BaADT10d & $16 \pm 0.2$ & 22.5 & 3.12 & 0.3 & 22.65 & 544 \\
\hline CuCDTOd & $16 \pm 0.2$ & 22.5 & 2.41 & 0.4 & 11.13 & 267 & CuADTOd & $16 \pm 0.5$ & 22.5 & 2.70 & 0.4 & 14.88 & 357 \\
\hline CuCDT3d & $16 \pm 0.2$ & 22.5 & 2.50 & 0.4 & 12.18 & 292 & CuADT3d & $16 \pm 0.5$ & 22.5 & 2.73 & 0.4 & 15.45 & 378 \\
\hline CuCDT5d & $16 \pm 0.2$ & 22.5 & 2.63 & 0.4 & 13.87 & 333 & CuADT5d & $16 \pm 0.5$ & 22.5 & 2.79 & 0.4 & 16.28 & 391 \\
\hline CuCDT7d & $16 \pm 0.2$ & 22.5 & 2.71 & 0.4 & 15.03 & 361 & CuADT7d & $16 \pm 0.5$ & 22.5 & 2.87 & 0.4 & 17.58 & 422 \\
\hline CuCDT10d & $16 \pm 0.2$ & 22.5 & 2.84 & 0.4 & 17.11 & 411 & CuADT10d & $16 \pm 0.5$ & 22.5 & 2.90 & 0.4 & 18.23 & 438 \\
\hline MaCDTOd & $16 \pm 0.5$ & 25 & 2.57 & 0.5 & 13.06 & 314 & MaADTOd & $16 \pm 0.7$ & 25 & 2.76 & 0.4 & 15.80 & 379 \\
\hline MaCDT3d & $16 \pm 0.5$ & 25 & 2.70 & 0.5 & 14.92 & 358 & MaADT3d & $16 \pm 0.7$ & 25 & 2.80 & 0.4 & 16.44 & 395 \\
\hline MaCDT5d & $16 \pm 0.5$ & 25 & 2.80 & 0.5 & 16.44 & 395 & MaADT5d & $16 \pm 0.7$ & 25 & 2.91 & 0.4 & 18.30 & 419 \\
\hline MaCDT7d & $16 \pm 0.5$ & 25 & 2.90 & 0.5 & 18.17 & 436 & MaADT7d & $16 \pm 0.7$ & 25 & 3.00 & 0.4 & 20.09 & 482 \\
\hline MaCDT10d & $16 \pm 0.5$ & 25 & 3.01 & 0.5 & 20.29 & 487 & MaADT10d & $16 \pm 0.7$ & 25 & 3.03 & 0.4 & 20.78 & 499 \\
\hline SeCDTOd & $16 \pm 0.1$ & 22.5 & 2.75 & 0.4 & 15.70 & 377 & SeADTOd & $16 \pm 0.5$ & 22.5 & 2.98 & 0.4 & 19.69 & 473 \\
\hline SeCDT3d & $16 \pm 0.1$ & 22.5 & 2.80 & 0.4 & 16.44 & 395 & SeADT3d & $16 \pm 0.5$ & 22.5 & 3.02 & 0.4 & 20.49 & 498 \\
\hline SeCDT5d & $16 \pm 0.1$ & 22.5 & 2.89 & 0.4 & 17.99 & 432 & SeADT5d & $16 \pm 0.5$ & 22.5 & 3.11 & 0.4 & 22.42 & 538 \\
\hline SeCDT7d & $16 \pm 0.1$ & 22.5 & 3.08 & 0.4 & 21.76 & 522 & SeADT7d & $16 \pm 0.5$ & 22.5 & 3.21 & 0.4 & 24.78 & 595 \\
\hline SeCDT10d & $16 \pm 0.1$ & 22.5 & 3.16 & 0.4 & 23.57 & 566 & SeADT10d & $16 \pm 0.5$ & 22.5 & 3.24 & 0.4 & 25.53 & 613 \\
\hline
\end{tabular}

$T_{b}=$ Base temperature, $T_{o}=$ Optimum temperature; $\log \left(\theta_{T}(50)\right)=\log$ thermal time $50 \%$ germination in ${ }^{\circ} d ; \sigma \theta_{T}=$ standard deviation of the log thermal time distribution within the seed population in ${ }^{\circ} \mathrm{d} ; \theta_{\mathrm{T}}(50)=$ thermal time $50 \%$ germination in ${ }^{\circ} \mathrm{d}$ and ${ }^{\circ} \mathrm{h}$, respectively

influence of the factors studied (Table 1), and there was an inverse relationship (Cor. Coeff: $-0.99, \mathrm{p}<0,05$ ) between the number of dark days and the germination response within the same population and thermal regimes (Table 2). This difference was observed between the DT0d versus DT10d. Regarding the origin of the seeds, there were no significant differences between $\mathbf{C u}$ and $\mathbf{M a}$, but differences did exist between $\mathbf{B a}$ and $\mathbf{S e}$, and those two together were significantly different from $\mathbf{C u}$ and $\mathbf{M a}$ together. (Table 2). $\mathbf{C u}$ and $\mathbf{M a}$ had the highest values, while Se had the lowest germination responses.

\section{Thermal model}

The differences in the thermal regimes depended on the mean temperature $\left(\mathrm{T}_{\mathrm{m}}\right)$ of each regime. In Figs. 1 and 2, the relationships are shown between $\mathrm{GR}_{50}$ and cattail seeds of distinct populations, thermal regimes and darkness treatments. The mean value of $\mathrm{T}_{\mathrm{b}}$ was $16.4 \pm 0.2^{\circ} \mathrm{C}$ with a minimum of $16.1^{\circ} \mathrm{C}$ and a maximum of $16.7^{\circ} \mathrm{C}$. This value explained why no germination occurred in the thermal treatments lower than $17.5^{\circ} \mathrm{C}$ and the lowest values of the germination responses occurred in the thermal treatments closest to $\mathrm{T}_{\mathrm{b}}$ (Table 2).
In Fig. 3, the relationships are shown between GR of different percentiles $(30,50$ and $70 \%)$ and $\mathrm{T}_{\mathrm{m}}$ of different populations with constant and alternating temperatures and treatments without $24 \mathrm{~h}$ dark photoperiod (DT0d). In thermal regimes within constant temperatures (Fig. 3a), both $\mathbf{M a}$ and $\mathbf{B a}$ had a $\mathrm{T}_{\mathrm{o}}=25^{\circ} \mathrm{C}$ in the three percentiles of GR, while $\mathbf{C u}$ and Se had a $\mathrm{T}_{\mathrm{o}}=$ $22.5^{\circ} \mathrm{C}$. In the regimes with alternating temperatures (Fig. 3b), only Ma had a $\mathrm{T}_{\mathrm{o}}=25^{\circ} \mathrm{C}$, while the remaining populations had $\mathrm{T}_{\mathrm{o}=} 22.5^{\circ} \mathrm{C}$. The $\mathrm{T}_{\mathrm{o}}$ was $22.5^{\circ} \mathrm{C}$, but the optimum temperature difference $\left(\Delta \mathrm{T}_{\mathrm{o}}\right)=2.5^{\circ} \mathrm{C}$ was found in the Ma population with constant and alternating temperatures and the $\mathbf{B a}$ population at constant temperatures (Fig. 3).

The thermal regimes with $\mathrm{T}_{\mathrm{m}}$ and the temperature difference $(\Delta \mathrm{T})=0{ }^{\circ} \mathrm{C}$ close to $\mathrm{T}_{\mathrm{b}}$ achieved the lowest germination responses in all the treatments, while the thermal regimes at temperatures close to $T_{o}$ showed the highest responses. The highest germination responses were observed in treatments with $\Delta \mathrm{T}=0^{\circ} \mathrm{C}$. The germination responses in the thermal regimes with the same $\mathrm{T}_{\mathrm{m}}$ but with $\Delta \mathrm{T}=5^{\circ} \mathrm{C} / 10^{\circ} \mathrm{C}$ were lower than $\Delta \mathrm{T}=$ $0^{\circ} \mathrm{C}$, while the germination in thermal regimes with 


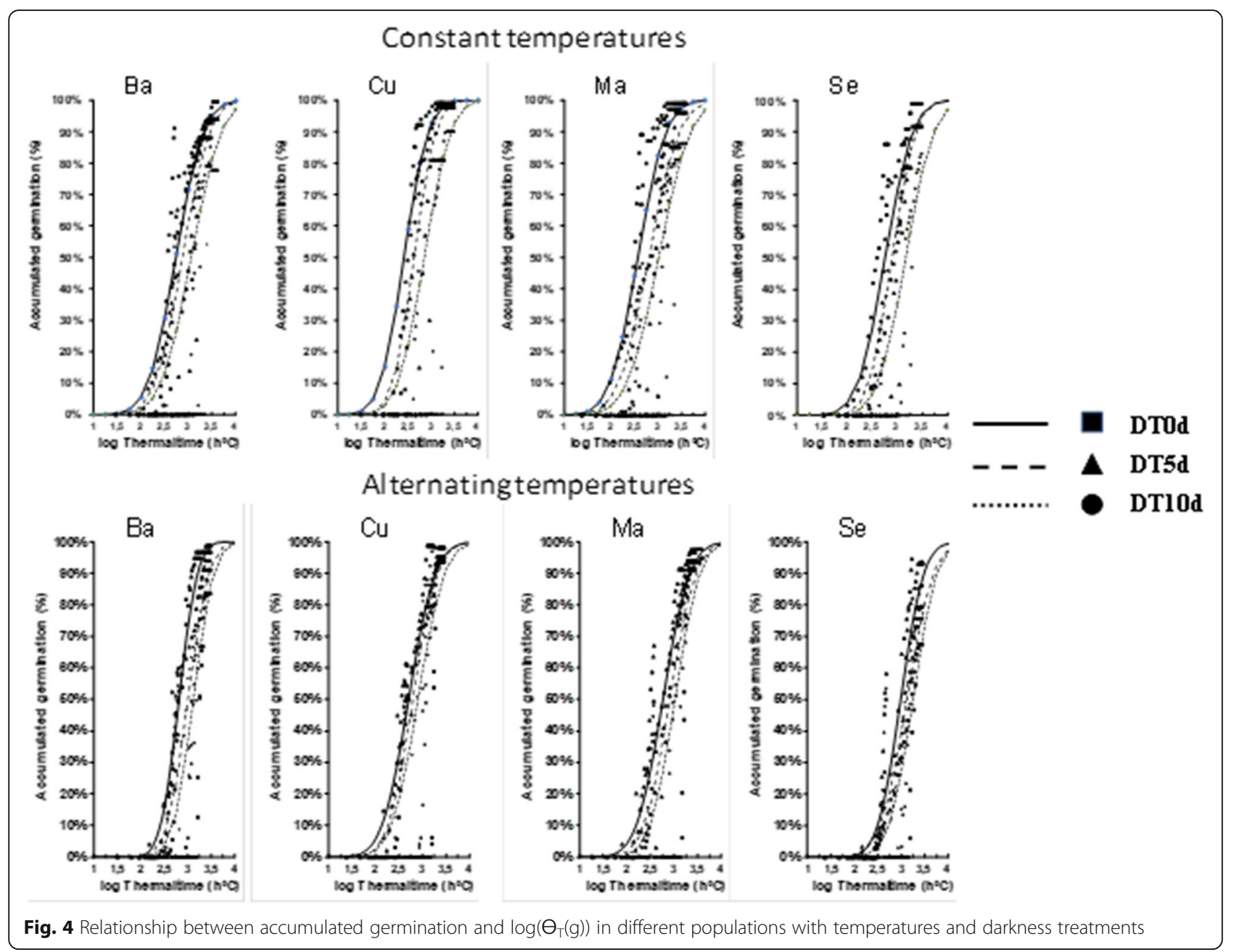

$\Delta \mathrm{T}=15^{\circ} \mathrm{C}$ was much closer to the germination with $\Delta \mathrm{T}=0{ }^{\circ} \mathrm{C}$ (Table 2).

The values of $T_{o}$ with different darkness periods were the same as those at DT0d (Table 3). The highest values of $\mathrm{GR}_{50}(0.34)$ were reached within constant regimes

Table 4 Relationship between $\log \left(\theta_{\top}(50)\right)$ and darkness treatments (DT) in treatments with the same population and amplitude of temperature regimes

\begin{tabular}{llll}
\hline Code & $\mathrm{A}$ & $\mathrm{b}$ & $\mathrm{R}^{2}$ \\
\hline $\mathrm{BaC}$ & 2.71 & 0.034 & 0.993 \\
$\mathrm{BaA}$ & 2.83 & 0.031 & 0.965 \\
$\mathrm{CuC}$ & 2.39 & 0.044 & 0.986 \\
$\mathrm{CuA}$ & 2.69 & 0.022 & 0.927 \\
$\mathrm{MaC}$ & 2.57 & 0.045 & 0.996 \\
$\mathrm{MaA}$ & 2.75 & 0.030 & 0.910 \\
$\mathrm{SeC}$ & 2.71 & 0.045 & 0.908 \\
$\mathrm{SeA}$ & 2.96 & 0.029 & 0.938 \\
\hline
\end{tabular}

$\log \left(\theta_{\mathrm{T}}(50)\right)=a+b^{*}($ DT $)$ close to $\mathrm{T}_{\mathrm{o}}\left(22.5 / 25^{\circ} \mathrm{C}\right)$ in all populations (Fig. 3a). In alternating regimes (Fig. 3b), these values are all approximately 0.23 in $\mathrm{T}_{\mathrm{o}}=25^{\circ} \mathrm{C}$. ANOVA of alternating temperatures indicated significant differences between thermal treatments $\left(\mathrm{F}_{(5,61)}=9.17, \mathrm{p}<0,001\right)$; therefore, the thermal treatments $15 / 30{ }^{\circ} \mathrm{C}$ and $20 / 25^{\circ} \mathrm{C}$ showed different values of three percentiles of GR (30,50 and $70 \%)$. Although they had the same mean temperature $\left(\mathrm{T}_{\mathrm{m}}\right)$, this difference could be related to the different ranges utilized in alternating temperatures $\left(15\right.$ and $5{ }^{\circ} \mathrm{C}$, respectively).

In Fig. 4, the relationship between accumulated germination and $\log \left(\theta_{\mathrm{T}}(50)\right)$ in the different thermal regimes $(\mathrm{C}$ and $\mathrm{A})$, populations and darkness treatments are shown. The curves of the models within the same population were close but not equal, and slight differences were observed between different darkness treatments and between thermal regimes with constant versus alternating temperatures. The curves of the regimes with alternating temperatures shift to the right when compared with those of constant temperatures. 
Table 5 Codes, population name, geographic coordinates and temperatures of five locations where seeds were collected

\begin{tabular}{|c|c|c|c|c|c|c|}
\hline Code & Population & Latitude & Longitude & $\begin{array}{l}\text { MATo }{ }_{a x} \\
\left({ }^{\circ} \mathrm{C}\right)\end{array}$ & $\begin{array}{l}\text { MATO } \\
\left({ }^{\circ} \mathrm{C}\right) \\
\end{array}$ & $\begin{array}{l}M^{M} \mathrm{To}_{\text {in }} \\
\left({ }^{\circ} \mathrm{C}\right. \\
\end{array}$ \\
\hline $\mathrm{Ba}$ & Puebla de Alcocer, Badajoz & $38^{\circ} 59^{\prime} \mathrm{N}$ & $5^{\circ} 15^{W} \mathrm{~W}$ & 23.8 & 17.1 & 10.3 \\
\hline $\mathrm{Cu}$ & Olmedilla del campo, Cuenca & $40^{\circ} 03^{\prime} \mathrm{N}$ & $2^{\circ} 42^{W} \mathrm{~W}$ & 19.3 & 13.1 & 6.9 \\
\hline Ma & Ciudad Universitaria, Madrid & $40^{\circ} 26^{\prime} \mathrm{N}$ & $3^{\circ} 44^{\prime} \mathrm{W}$ & 19.9 & 15.0 & 10.1 \\
\hline Se & Lantejuela, Seville & $37^{\circ} 21^{\prime} \mathrm{N}$ & $5^{\circ} 13 \mathrm{~W}$ & 25.4 & 19.2 & 13.0 \\
\hline To & Seseña, Toledo & $40^{\circ} 04^{\prime} \mathrm{N}$ & $3^{\circ} 37 \mathrm{~W}$ & 22.1 & 15.8 & 9.5 \\
\hline
\end{tabular}

MATo $_{a x}$ (yearly mean maximum temperature); MATo (yearly mean temperature) and MATo ${ }_{\text {in }}$ (yearly mean minimum temperature). Historical data obtained from The State Meteorological Agency of Spain [47]

There were similar values of $0_{\mathrm{T}}$ (standard deviation of the log thermal time) in all treatments (Table 3) which means that final germination $(50 \%)$ was reached in all treatments.

The treatments of the same population and darkness treatments in thermal regimes with constant temperatures showed lower values of thermal time (Table 3 ) in comparison with regimes of alternating temperatures. The thermal time was influenced by the darkness treatments because, for all populations, and all temperature levels and temperature amplitudes, it was seen to increase the more days the seeds were kept in darkness(Cor. Coeff: $-0.99, \mathrm{p}<0,05)$. According to these results, there was a relationship between $\log \left(\theta_{\mathrm{T}}(50)\right)$ and the set

Table 6 Evaluation of the thermal time models. Difference between $\log \left(\theta_{T}(\mathrm{~g})\right)$ (expected values) versus $\log \left(\theta_{T}(\mathrm{~g})\right)_{\mathrm{T}}$ (observed values)

\begin{tabular}{llllll}
\hline CODE & $R^{2}$ & Std Err & CODE & $R^{2}$ & Std Err \\
\hline BaCDT0d & 0.91 & 0.13 & BaADT0d & 0.91 & 0.09 \\
BaCDT3d & 0.84 & 0.12 & BaADT3d & 0.86 & 0.10 \\
BaCDT5d & 0.81 & 0.13 & BaADT5d & 0.84 & 0.11 \\
BaCDT7d & 0.79 & 0.13 & BaADT7d & 0.83 & 0.11 \\
BaCDT10d & 0.80 & 0.22 & BaADT10d & 0.82 & 0.12 \\
CuCDT0d & 0.94 & 0.06 & CuADT0d & 0.90 & 0.14 \\
CuCDT3d & 0.82 & 0.11 & CuADT3d & 0.82 & 0.14 \\
CuCDT5d & 0.81 & 0.08 & CuADT5d & 0.81 & 0.13 \\
CuCDT7d & 0.77 & 0.11 & CuADT7d & 0.81 & 0.13 \\
CuCDPT10d & 0.77 & 0.13 & CuADPT10d & 0.80 & 0.13 \\
MaCDT0d & 0.87 & 0.16 & MaADT0d & 0.85 & 0.12 \\
MaCDT3d & 0.83 & 0.14 & MaADT3d & 0.82 & 0.12 \\
MaCDT5d & 0.81 & 0.18 & MaADT5d & 0.78 & 0.18 \\
MaCDT7d & 0.81 & 0.18 & MaADT7d & 0.80 & 0.27 \\
MaCDT10d & 0.81 & 0.15 & MaADT10d & 0.80 & 0.16 \\
SeCDT0d & 0.94 & 0.09 & SeADT0d & 0.91 & 0.10 \\
SeCDT3d & 0.83 & 0.05 & SeADT3d & 0.85 & 0.08 \\
SeCDT5d & 0.82 & 0.11 & SeADT5d & 0.79 & 0.23 \\
SeCDT7d & 0.78 & 0.18 & SeADT7d & 0.79 & 0.27 \\
SeCDT10d & 0.78 & 0.11 & SeADT10d & 0.78 & 0.23 \\
\hline
\end{tabular}

of darkness treatments (Table 4) characterized by an $\mathrm{R}^{2}>0.90$.

There were also differences between $\theta_{\mathrm{T}}(50)$ according to populations (Table 3 ). The lowest $\theta_{\mathrm{T}}$ (50) time (Table 3) corresponded to $\mathbf{C u}$, which coincided with the lowest yearly maximum, mean and minimum ambient temperatures (Table 5). Ma had $\theta_{\mathrm{T}}$ (50) higher than that of $\mathbf{C u}$ with ambient temperatures slightly higher than those in $\mathbf{C u}$, while Se and Ba had the highest $\theta_{\mathrm{T}}(\mathrm{g})$ (Table 3) and the highest ambient temperatures (Table 5).

The results of the evaluation of the thermal time models are shown in Table 6 . The coefficient of determination $\left(R^{2}\right)$ was the concordance between $\log \left(\theta_{T}(g)\right)$ of each model (expected values in each model) and $\log \left(\theta_{\mathrm{T}}(\mathrm{g})\right)_{\mathrm{To}}$ (observed values). Results of $\mathrm{R}^{2}$ varied depending on thermal regimes and darkness treatments. A good concordance was found in all treatments with $R^{2}$ values greater than 0.77 . The highest values of $R^{2}(\geq$ 0.90) corresponded to treatments without $24 \mathrm{~h}$ dark photoperiod (DT0d) in all populations and thermal regimes except Ma population ( 0.87 and 0.85 respectively), which implied a strong coincidence between expected and obtained values. $R^{2}$ values decreased in treatments with $24 \mathrm{~h}$ dark photoperiod (DT3d, DT5d, DT7d and DT10d).

\section{Discussion}

The successful establishment of a plant species in a location is closely related to the rapidity of germination. Different genotype and/or environmental factors can affect this process by increasing or decreasing this rate. Amongst the environmental factors, light is one that does not prevent the germination of seeds, if it acts as a signal [25] to cause a change in the germination rate and final germination [31] and, therefore, in thermal time parameters. This factor is one of the main determinants of the accumulation of a persistent seed bank of numerous weeds in the soil [48], and it is necessary for the germination of many species [31] mainly of plants with small seeds [31, 48] because large seeds can emerge from a much greater depth than light can penetrate [49]. Exposure time to light may be short, less than a minute, or long. Short exposure time is more commonly effective 
with small weed seeds, such as cattail seeds, than with large weeds [31].

Light exposure influences the germination of different Typha species $[5,50]$. In this work, no germination was obtained in DT20d treatments and a delay in the germination was observed in treatments with a $24 \mathrm{~h}$ dark photoperiod (DT3d to DT10d). This effect may be explained by the development of a secondary dormancy related to phytochrome activation/deactivation processes which occur through the stimulus of light on cattail seeds. Phytochromes are the principal mechanism triggering germination of Typha because they participate in breaking the dormancy [22, 25]. These pigments have two mutually photoconvertible forms: Pfr (considered the active form for seed germination) and $\operatorname{Pr}$ (considered the inactive form) [25, 49]. Pfr is established during the formation of the seed in the mother plant; however, this phytochrome form can reconvert to Pr in darkness [18, 31]. In these circumstances, the secondary dormancy does not break, and a period is needed to reconvert the phytochrome to its active form (Pfr) [51, 52]. This secondary dormancy can explain the results in darkness treatments. For example, in the darkness treatments (DT3d to DT10d), thermal time increases as the number of days in darkness increases (Table 4). In the case of DT20d treatments, no germination was measured after 20 days in darkness. These cattail seeds, although they absorbed water and began to swell, did not break their coatings to allow germination. This may explain the death of every seed after 20 days in darkness or the delay produced by secondary dormancy. We support this second option but, since no subsequent germination data was collected, a further study would be necessary to determine it.

Treatments of the same population had an increase in $\theta_{\mathrm{T}}(50)$ as the number of days in darkness increased. There was a relationship between $\log \left(\theta_{\mathrm{T}}(50)\right)$ and darkness treatments $\left(R^{2}>0.90\right)$ (Table 4$)$. Initially, a linear increase in thermal time was expected as the number of days in darkness increased. Indeed, there was an increase, but it was not proportional; for example, in the case of the population of $\mathbf{C u}$ with constant temperatures, $\theta_{\mathrm{T}}(50)$ at PTOd was $267^{\circ} \mathrm{h}$, and the value corresponding to DT10d was $411{ }^{\circ} \mathrm{h}$. This means a $50 \%$ increase in thermal time, not a $100 \%$ increase as expected. This modification would indicate that $T$. domingensis seeds accumulate hours of temperature and that when receiving light, the dormancy is broken by the activation of Prf and the germination response occurs more quickly than expected. Darkness treatments, such as DT3d, DT5d, DT7d and DT10d, had lower seed germination than treatments without $24 \mathrm{~h}$ dark photoperiod (DT0d). These results indicate that long days of darkness may decrease the light sensitivity of $T$. domingensis.
Dormancy broken in the presence of light and the influence of phytochrome has been studied and is common in small seeds, such as cattails [22, 52]. A buried environment is associated with darkness and cattail seeds do not germinate in darkness at any temperature; hence, buried seeds of $T$. domingensis could be a control method for the establishment in aquatic ecosystems. Darkness is also related to the depth of water [25]; so the establishment of cattails in the GFF system may be successful if seeds are sowed above the soil submerged in water or on a floating structure of this system.

Although water depth was not a factor in this study, it is another factor that is related to the amount of light and the ease of germination of cattail seeds. The depth used was enough to saturate the paper and seed $(<0.4$ $\mathrm{cm})$ due to the fact that germination in cattail seeds is greater and faster in aquatic conditions [2, 24, 33]. Some authors have stated that flooded areas increase the germination of Typha species, and this increase in germination has a direct relation to depth $[17,53]$. This feature may be caused by a decrease in the level of oxygen, rather than by the lower intensity of light in these situations [33]. Other studies, however, show no relationship between the germination rate and depth [34, 54]. The limit of the depth of germination in Typha species in clear water is around $40 \mathrm{~cm}$ [2] or $1 \mathrm{~cm}$ in sediment [55]. There is an extreme case where cattail seeds germinated under $80 \mathrm{~cm}$ water (and survived 8 weeks) [56].

The germination response in plants of different origins could also be different [49]. Differences related to the origin of a population are frequent in numerous species of plants, whether crops [57] or weeds [27, 58]. Successfully colonizing a new location is related to the greater adaptive capacity of these populations to harsher environmental conditions compared to other populations [59], thus allowing these populations to have greater flexibility and adaptability to different locations or future climate change scenarios [17].

Cattail seeds were grouped into northern $(\mathbf{C u}$ and $\mathbf{M a})$ and southern (Ba and Se) populations (Fig. 5). Mean temperatures of germination within each group were similar, but there were differences between the groups. The northern populations have lower values than the southern populations (Table 5). The results of the thermal time study also show differences between northern and southern populations. In treatments with the same temperature and darkness periods, the northern population presented lower values of thermal time and a higher germination response than the southern populations (Tables 2 and 3).

These differences among populations are consistent with the results of other studies carried out with Typha latifolia L. in fifteen European populations [17] and USA populations [60]; in both studies, in comparison to 


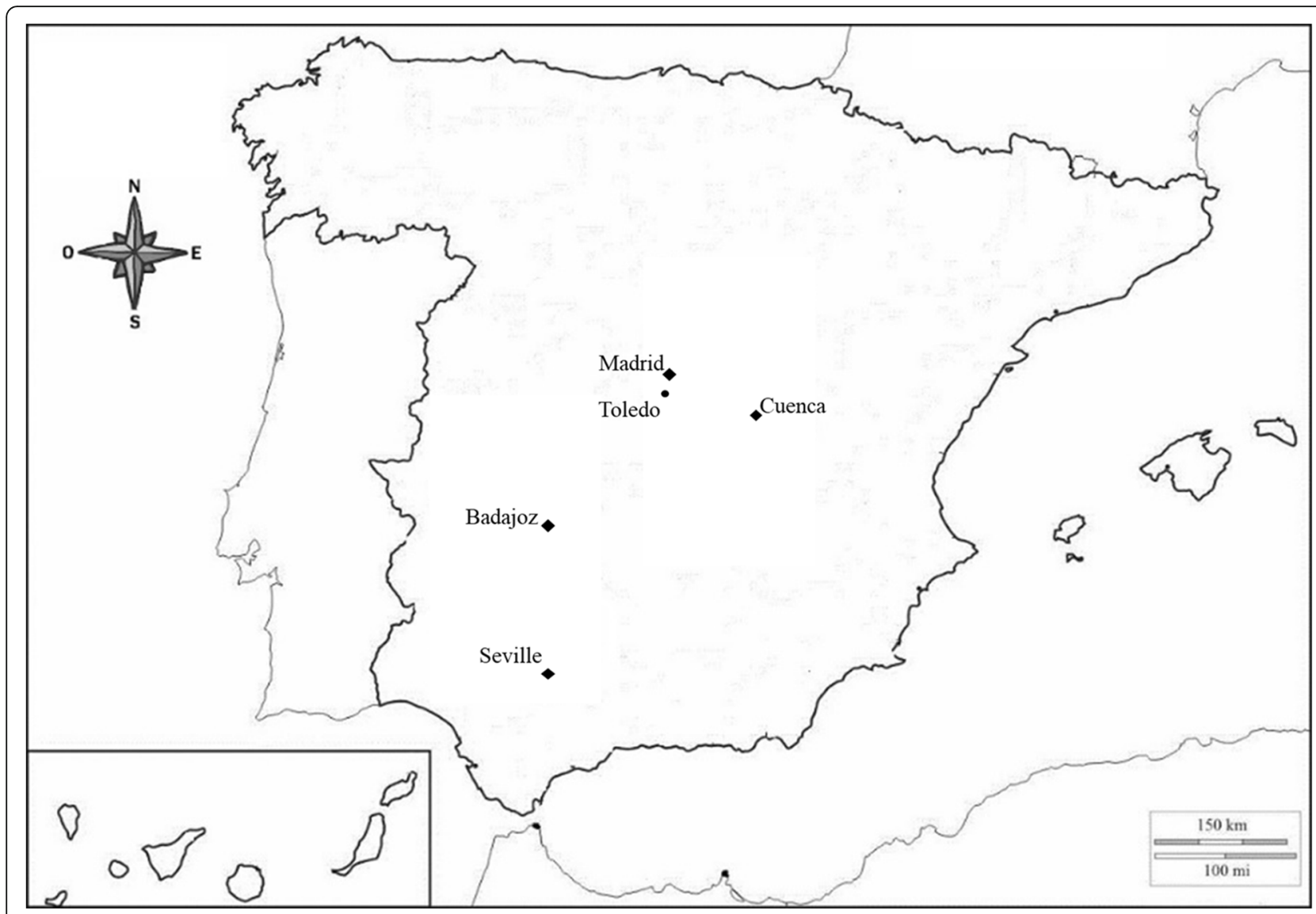

Fig. 5 Origin of the populations of T. domingensis used in this work. Puebla de Alcocer, Badajoz (Ba); Olmedilla del Campo, Cuenca (Cu); Lantejuela, Seville (Se), the macrophytes nursery of GA, Madrid (Ma) and Seseña (To). To population was used to validate the thermal time parameters

northern populations, southern populations germinated at a lower temperature. However, in our study, the opposite scenario occurred. Before providing conclusions, some points concerning these studies must be clarified. For example, $T$. domingensis is a species more adapted to warmer areas compared to T. latifolia. In the European study, only two Mediterranean populations were used, and both populations germinated more rapidly than northern populations; the distances between the origins of the populations were greater than those in our study. Some authors mention that other factors, such as temperature or nutrient supply, are more important than the origin of the seeds in the case of neighbouring populations [17].

In this study, the estimated mean $\mathrm{T}_{\mathrm{b}}$ was $16.4^{\circ} \mathrm{C}$ and no differences greater than $0.6^{\circ} \mathrm{C}$ were observed regardless of origin, darkness treatments, or level or amplitude of temperatures. We could have considered that $\mathrm{T}_{\mathrm{b}}$ was constant; however, other studies with crops [46] or weeds [61] estimated different $T_{b}$ values for the different amplitudes of temperatures. There were significant differences in the germination responses both in terms of the level and amplitude of temperatures (Table 2). In comparison to treatments with other $\mathrm{T}_{\mathrm{m}}$, treatments with $\mathrm{T}_{\mathrm{m}}$ close to $\mathrm{T}_{\mathrm{b}}$ achieved a lower germination response in all treatments (Table 2). No data were found for the calculated $\mathrm{T}_{\mathrm{b}}$ for Typha species, but the estimated values of $T_{b}$ for cattail seeds in this study were very similar to those obtained in other studies with summer weeds $[29,62]$. Steinmaus (2000) established a relation between the slope of the line used to estimate $T_{b}$ and germination rate; this rate will be greater with a higher slope. In our study, higher slopes occurred in $\mathbf{C u}$ in thermal regimes with both constant and alternating temperatures and coincided with the lower $\theta_{\mathrm{T}}(50)$ of all populations studied (Figs. 1 and 2).

Differences in $T_{o}$ were obtained in the results of the multifactor analysis, mainly between the northern $(\mathbf{C u}$ and $\mathbf{M a}$ ) and southern populations (Ba and Se) (Table 4). This difference in $T_{o}$ is comparable with the results of other studies with different populations of weeds or with $T$. latifolia $[17,22,23]$. The $\mathrm{T}_{\mathrm{o}}$ for the Swedish populations of $T$. latifolia was approximately $20^{\circ} \mathrm{C}$ [23] or $10 / 30^{\circ} \mathrm{C}$ with alternating temperatures in Italian 
populations [22]. Australian populations of the Typha genus germinate readily at high temperatures and decline when the $\mathrm{T}_{\mathrm{m}}$ is lower than $20^{\circ} \mathrm{C}$ [63].

Table 7 shows the results from different studies of the seed germination of $T$. latifolia and $T$. domingensis. There are few studies on the seed germination of $T$. domingensis. Lorenzen et al. (2000) stated that a $\mathrm{T}_{\mathrm{o}}$ of $30^{\circ} \mathrm{C}$ and $25 / 10^{\circ} \mathrm{C}$ occurred in south-eastern American populations of $T$. domingensis at constant and alternating temperatures, respectively. These $T_{o}$ values are distinct from those obtained in our study $\left(22.5-25^{\circ} \mathrm{C}\right)$, but there are other studies with $\mathrm{T}_{\mathrm{o}}$ values very similar to those obtained in this work (Table 7). These results showed different $T_{o}$ values according to the places of origin of the seed and were closely related to climatic conditions at each location [17]. Some conditions, such as the temperature of the mother plants [38, 65], may determine the germination of populations, regardless of whether the seeds were of the same species [24, 37].

In the Typha genus, temperature and amplitude were shown to be factors related to germination [23]. The favourable effect of alternating temperatures on the germination response is well known in different weeds [22] because the effect enables a seed to understand when it is buried and to inhibit germination. In nature, seeds of the cattail are usually submerged. In this situation, fluctuations in the ambient temperature are rare; therefore, an increase in this fluctuation could indicate that seeds have reached land and germination could be stimulated. In this study, both thermal factors (level and fluctuation in temperatures) influenced the final germination of cattail seeds. In the treatments within the same population and in the darkness treatment, there was a greater germination response as the temperature approached $T_{o}$ from values close to $T_{b}$, causing the existence of significant differences depending on the temperature level (Tables 1 and 2). An increase in the germination response is obtained with higher temperatures up to $\mathrm{T}_{\mathrm{o}}$; above this value, germination begins to decrease. The same results occur in other studies with Typha [17, 22, 23, 33] and weeds $[27,29]$.

The use of different amplitudes of temperature is related to the loss of dormancy in weeds $[29,66]$ or crops such as lentil [30]. In the case of cattail seeds, the loss of dormancy is related to changes in germination responses. Treatments with $\Delta \mathrm{T}=0^{\circ} \mathrm{C}$ and $15^{\circ} \mathrm{C}$ had a higher germination response than those with $\Delta \mathrm{T}=5^{\circ} \mathrm{C}$ and $10^{\circ} \mathrm{C}$ (Table 1), so these last two amplitudes of temperature negatively affect germination. However, in studies with $T$. latifolia, treatments with constant temperature regimes $\left(\Delta \mathrm{T}=0^{\circ} \mathrm{C}\right)$ achieved a lower germination response than alternating regimes $\left(\Delta \mathrm{T}>0^{\circ} \mathrm{C}\right)$ [17]. On the other hand, $\theta_{\mathrm{T}}$ (50) corresponds to treatments of the same population, and $\Delta \mathrm{T}=0^{\circ} \mathrm{C}$ is lower than treatments with $\Delta \mathrm{T} \geq 0{ }^{\circ} \mathrm{C}$ (Fig. 4), in contrast to Solanum physalifolium [29] whose thermal time is considerably reduced in an alternating regime (Table 3 ). These data are consistent with the germination rate (Fig. 3 ), in which treatments with alternating temperatures reach lower values than those corresponding to constant temperatures. According to these results, the best season to germinate $T$. domingensis would be late spring because these seasons have a temperature regime of approximately $\Delta \mathrm{T}=15^{\circ} \mathrm{C}$ under natural conditions in the five locations where seeds were collected [47].

The thermal time value of different populations of cattail seeds (Table 3) was substantially lower than that of other weeds such as different species of Solanum [20, 22] or tropical species such as Pennisetum typhoydes [45, 67]. This indicates a rapid germination response compared with those of other plant species. There were also differences between populations, with $\mathbf{C u}$ being the one with the lowest thermal time, both in $\Delta \mathrm{T}=0$ and $\Delta \mathrm{T}>0$ treatments. Although $\mathbf{C u}$ and $\mathbf{M a}$ obtained similar germination values (Table 2), $\theta_{\mathrm{T}}(50)$ was the highest in Ma.

Therefore, $\mathbf{C u}$ could be the population that presents the most vigour during this process because this population had the fastest germination under the conditions

Table 7 Optimal temperature in T. domingensis and T. latifolia in different populations from various studies

\begin{tabular}{|c|c|c|c|c|}
\hline Plant species & Reference & C & A & Seed location \\
\hline \multirow[t]{3}{*}{ Typha domingensis } & This study & $22.5 ; 25^{\circ} \mathrm{C}$ & & Spain \\
\hline & Lorenzen et al. (2000) [5] & $30^{\circ} \mathrm{C}$ & $25 / 10^{\circ} \mathrm{C}$ & Florida, U.S. \\
\hline & Royal Botanic Gardens (2002) [64] & $20^{\circ} \mathrm{C}$ & & Wakehurst, England \\
\hline \multirow[t]{6}{*}{ Typha latifolia } & Sifton H.B (1959) [50] & $30^{\circ} \mathrm{C}$ & $20 / 30^{\circ} \mathrm{C}$ & Ontario, Canada \\
\hline & Bonnewell, V. et al. (1983) [33] & $35^{\circ} \mathrm{C}$ & & Minnesota, U.S. \\
\hline & Lombardi, T et al. (1997) [22] & & $20 / 30^{\circ} \mathrm{C}$ & Pisa, Italy \\
\hline & Ekstam and Forseby (1999) [23] & $20^{\circ} \mathrm{C}$ & & Linköping, Sweden \\
\hline & Heinz, S (2011) & $25^{\circ} \mathrm{C}$ & $10 / 25^{\circ} \mathrm{C}$ & Germany \\
\hline & Meng, H. et al. (2016) [24] & & $25 / 15^{\circ} \mathrm{C}$ & Northeast of China. \\
\hline
\end{tabular}


tested. The final germination percentages were very similar in all populations. It would be necessary to carry out new tests to determine whether the development in other stages of plant growth would also be fast in this population.

In comparison to other species of the genus, such as $T$. angustifolia, $T$. domingensis is a plant species more adapted to warm temperatures. In Spain, it has been observed that $T$. domingensis has been colonizing places where T. angustifolia once stood [3]. If this capacity occurs with an increase in temperatures due to climate change, then it is possible to consider that $T$. domingensis might increase its expansion to the detriment of other Typha species such as T. angustifolia.

According to the evaluation of the models developed in this work (Table 6), there were some differences between the results that were related to thermal regimes and darkness treatments. The greatest coincidences are in the models developed with constant and alternating thermal regimes and DT0d treatments with $R^{2}$ mean values $\geq 0.9$, except for the population of Ma that present values slightly below 0.9 in both thermal regimes. The best coincidence was between expected and observed values in constant regimes and treatments without $24 \mathrm{~h}$ dark photoperiod (DT0d). Darkness treatments affect the coincidence between expected and observed values, the $R^{2}$ decreased to mean values between 0.84 to 0.78 . In the DT3d treatments, $R^{2}$ values were greater than the other darkness treatments. In the remaining darkness treatments (DT5d, DT7d and DT10d), $\mathrm{R}^{2}$ values were similar (Table 6). Ba and Ma populations show both the most and least coincidental values in all treatments, respectively, but the differences were small among all populations.

This work shows that environmental factors and the origin of populations affect the germination responses of cattail seed; moreover, how these parameters could be used to develop models that predicting seed behaviour in a new habitat.

\section{Conclusions}

The thermal time model for the different populations of $T$. domingensis allows an understanding of the germination response of each population established in a new habitat, such as a GFF system. The germination response of $T$. domingensis was affected by thermal regimes, darkness treatments, and populations.

Among the different populations of $T$. domingensis, $\mathrm{T}_{\mathrm{o}}$ in $\mathbf{M a}$ and $\mathbf{B a}$ were $25^{\circ} \mathrm{C}$, and those in $\mathbf{C u}$ and Se were $22.5^{\circ} \mathrm{C}$. However, the $\mathrm{T}_{\mathrm{b}}$ was the same in the four populations (mean $16.4 \pm 0.2^{\circ} \mathrm{C}$ ). Therefore, the best population can tolerate a vast range of temperatures in a new habitat was $\mathbf{C u}$ due to this population had the highest germination rates and the highest germination percentage. If growth chambers are used to proceed with the germination of $T$. domingensis seeds, then the most appropriate temperature treatment will be a constant temperature of $22.5^{\circ} \mathrm{C}$. Under natural conditions, the best time for seed germination occurs when there is a temperature regime of approximately $15^{\circ} \mathrm{C}$ in the Mediterranean zone such as Spain, which mainly occurs in the late spring. Values of $T_{m}$ near $T_{o}$ and $\Delta T$ values approximately to $15^{\circ} \mathrm{C}$ are common in the four populations; hence, these values show that $T$. domingensis could readily germinate in a new habitat and expand as a weed if an increase in the mean temperature occurs.

\section{Methods}

\section{Plant material}

The plant material used for this study was obtained and subsequently identified by experts of the Botany Unit of the Department of Agrarian Production (UPM). The Botanical key used was: Flora Iberica, Vol. XVIII, Gen. Typha [3]. T. domingensis is a species widely distributed throughout Spain. For this reason, no specimens were taken to be included in any Herbarium. According to the International Union for Conservation of Nature and Natural Resources (IUCN) Red List Categories, T. domingensis does not qualify as critically endangered, endangered, vulnerable or near threatened [68] so permissions were not necessary to collect samples.

The seed material for this study came from natural $T$. domingensis stands at five different locations in Spain (Fig. 5). For the thermal study, mature spadices were collected from Puebla de Alcocer (Ba), Olmedilla del Campo $(\mathbf{C u})$, and Lantejuela $(\mathbf{S e})$. The plants of these populations were located in naturally flooded areas (ponds, lagoons, and marshes) and in this study they are represented by $\mathbf{B a}, \mathbf{C u}$, and $\mathbf{S e}$, for plant populations from Badajoz, Cuenca and Seville, respectively (Table 5). Ma location was the fourth population. The seeds of this population were obtained from a macrophyte nursery in the experimental fields of GA, Madrid, whose initial source was the Manzanares River, which is very close to these facilities. The fifth population was collected in Seseña, Toledo (To). This population was used to evaluate the results of the thermal models obtained for the other populations. According to the classification of Köppen-Geiger, the five locations are classified as having temperate climates with dry and hot summers. The geographic coordinates and temperatures of the different locations are shown in Table 5 [47].

Mature spadices of these populations were collected from plants grouped into the pure mass of cattails between late summer and early autumn of 2017. These spadices were obtained from various $T$. domingensis plants (7-12 plants per population) that grew in the same physical location. The seeds of each spadix were 
Table 8 Thermal regimes and darkness period treatments used in the experiment

\begin{tabular}{|c|c|c|c|c|}
\hline \multicolumn{3}{|c|}{ Thermal regimes $\left({ }^{\circ} \mathrm{C}\right)$} & \multicolumn{2}{|c|}{ Darkness treatments } \\
\hline Treatments & $\mathrm{T}_{\mathrm{m}}$ & $\Delta T$ & Treatments & Description \\
\hline $\mathrm{C} 17.5$ & 17.5 & 0 & DTOd & 20 days with $12 \mathrm{~h}$ light /dark \\
\hline C 20.0 & 20 & 0 & DT3d & 3 days ( $24 \mathrm{~h}$ darkness) and 17 days ( $12 \mathrm{~h}$ light /dark) \\
\hline C 22.5 & 22.5 & 0 & DT5d & 5 days ( $24 \mathrm{~h}$ darkness) and 15 days ( $12 \mathrm{~h}$ light /dark) \\
\hline C 25.0 & 25 & 0 & DT7d & 7 days ( $24 \mathrm{~h}$ darkness) and 13 days ( $12 \mathrm{~h}$ light /dark) \\
\hline C 27.5 & 27.5 & 0 & DT10d & 10 days ( $24 \mathrm{~h}$ darkness) and 20 days ( $12 \mathrm{~h}$ light /dark) \\
\hline C 30.0 & 30 & 0 & DT20d & 20 days with $24 \mathrm{~h}$ darkness \\
\hline A $15 / 20$ & 17.5 & 5 & & \\
\hline A $15 / 25$ & 20 & 10 & & \\
\hline A $15 / 30$ & 22.5 & 15 & & \\
\hline A $20 / 25$ & 22.5 & 5 & & \\
\hline A $20 / 30$ & 25 & 10 & & \\
\hline A $25 / 30$ & 27.5 & 5 & & \\
\hline
\end{tabular}

mixed. In the laboratory, the seeds were removed from these spadices by agitating the fruits in water. Only seeds settling to the bottom of the container were selected as viable seeds for the germination test. Then, the selected seeds were dried on filter paper and stored in a refrigerator $\left(\right.$ at $5{ }^{\circ} \mathrm{C}$ ) until they were used in the germination test in the following year.

Previous experiments had been carried out to verify that most of the seeds were viable. Shortly before the experiment, the seeds were treated with $1 \%$ sodium hypochlorite to prevent infection during the assay [69], washed with sterile distilled water to eliminate any residue and dried rapidly at room temperature.

\section{Germination tests}

Germination tests were carried out in three identical growth chambers with two photoperiodic regimes: (i) 24 $\mathrm{h}$ darkness, the dishes were covered with aluminium foil and placed in black plastic bags to prevent the passage of light, and (ii) $12 \mathrm{~h}$ light / dark under continuous irradiation illuminated by 8 fluorescent sources of white light (Sylvania Grolux $35 \mathrm{~W}$ ). PAR was measured in different positions of the growth chamber (PAR sensor LI-CORDATALOGGER Inc.USA) at the beginning and the end of the experiments; the mean value was $85 \pm 9 \mu \mathrm{mol}$ $\mathrm{m}^{-2} \mathrm{~s}^{-1}$.

Different darkness treatments and thermal regimes on five cattail seed populations (Ba, $\mathbf{C u}, \mathbf{M a}, \mathbf{S e}$ and To) were studied as factors that could alter the final germination and the result of the germination model. The relationship between thermal time, temperature and darkness for the cattail seeds was studied. For this reason, different darkness treatments $(0,3,5,7,10$ and 20 dark days) were included in this study. The longest number of days was the same (20 days) for the seeds, so the number of days with $12 \mathrm{~h}$ light /dark photoperiod was reduced successively (Table 8 ). In the treatment DT20d, the seeds were incubated in total darkness for the entire time.

Different thermal regimes were included in this study. These regimes include different levels of constant or alternating temperatures, as explained below. The constant temperatures used $(C)$ were: 17.5, 20.0, 22.5, 25.0, 27.5 and $30.0{ }^{\circ} \mathrm{C}$; the alternating temperatures used (A) were $15 / 20,15 / 25,15 / 30,20 / 25,20 / 30$, and $25 / 30^{\circ} \mathrm{C}$. In the alternating regimes, higher temperatures coincide with light periods and lower temperatures with the dark period of each photoperiodic regime used, and the temperature difference $(\Delta \mathrm{T})$ between the dark and light periods was $\Delta \mathrm{T}=5,10$ and $15^{\circ} \mathrm{C}$ (Table 8). The mean value of both temperatures $\left(\mathrm{T}_{\mathrm{m}}\right)$ was used to calculate the models.

Temperatures above $30^{\circ} \mathrm{C}$ were not used because $T$. domingensis is a plant species whose germination season coincides with middle spring, so it would be very odd if the mean temperature above $30^{\circ} \mathrm{C}$ was reached at that time in the study area. The treatment name was composed of the name of the population, mean temperature value, letter of the temperature regime $\mathrm{C} / \mathrm{A}$ with a number that indicated the $\Delta \mathrm{T}$ and darkness treatment, such as Ba25C0DT5d and Ba25A10DT3d.

The experimental design was completely randomized. A total of 360 treatments were carried out and three replicates of 33 seeds each were used for each treatment. The germination test was conducted in a filter paperlined Petri dish filled with $15 \mathrm{ml}$ of distilled water. To prevent evaporation losses, the edges of the Petri dishes were closed using laboratory film. HOBO U12 (Onset Computer Corporation, Pocasset, MA, USA) data loggers were used to monitor the temperature inside the 
growth chambers. Data from the chamber were accepted if the temperature registered showed a difference of less than $\pm 0.5^{\circ} \mathrm{C}$. All treatments were set up at 9:00 h. Germinated seeds were counted daily for 20 days. A seed was considered to have germinated when the coleoptile broke the pericarp [22].

\section{Thermal time model}

Seed germination of different populations of $T$. domingensis was described as a function of the thermal time model. According to the model presented by GarciaHuidrobo et al. (1982), the parameter thermal time $\theta_{T}$ (degree-day/ degree-hour) for the percentile $\mathrm{g}$ is:

$$
\theta_{T}(g)=\left(T-T_{b}\right) t_{g}
$$

Another parameter defined in this model is the germination rate $\left(G R_{g}\right)$, which is the inverse of the time to radicle emergence of a specific percentile of the population defined by eq. 1 .

$$
G R_{g}=\frac{T-T_{b}}{\theta_{T}(g)}=\frac{1}{t_{g}}
$$

There is a linear regression line between $\mathrm{GR}_{\mathrm{g}}$ and $\mathrm{T}$ when the temperature is between $\mathrm{T}_{\mathrm{b}}$ and $\mathrm{T}_{\mathrm{o}}$. Under these circumstances, the slope of this linear regression is equal to the reciprocal of thermal time $\theta_{T}(\mathrm{~g})$. If the change in $\theta_{T}(\mathrm{~g})$ within a seed population is a log-normal distribution, then the relation between $\mathrm{GR}_{\mathrm{g}}$ and $\theta_{T}(\mathrm{~g})$ can be described using the probit function [46].

$$
\operatorname{prob}_{\mathrm{g}}=\left(\frac{1}{\sigma_{\theta_{\mathrm{T}}}}\right) \log \left(\mathrm{T}-\mathrm{T}_{\mathrm{b}}\right) \mathrm{t}_{\mathrm{g}}-\underline{\log \left(\theta_{\mathrm{T}}(50)\right)}
$$

In this function, prob $_{\mathrm{g}}$ is the probit transformation of the cumulative germination percentile $\mathrm{g}, \theta_{T}(50)$ is the thermal time to $50 \%$ germination, and $\sigma \theta_{T}$ is the standard deviation of $\theta_{T}$ for individual seeds in the population [70]. Alternative use of probit transformation is logistic transformation when the sample size is not very large. In this case, the midpoint of the logit regression (logit $=0$ ) is the same as that obtained with probit transformation, and the slope $(\alpha)$ is related to the standard deviation of the normal distribution $(\sigma)$ as defined [71] as:

$$
\sigma=\frac{\pi}{\sqrt{3}} * \frac{1}{\alpha}
$$

and the $\log \theta_{T}(50)$ is related to the intercept of the logit regression ( $\beta)[27]$ as:

$$
\log \left(\theta_{\mathrm{T}}(50)\right)=-\frac{\beta}{\alpha}
$$

Data from the different temperature regimes were normalized following the concept of thermal time basis
(Covell et al., 1986) where $\theta_{\mathrm{T}}(50)$ is the mean thermal time to $50 \%$ germination used for the log thermal time distribution that was estimated from the equation:

$$
\theta T_{(50)}=\frac{\left(T_{m}-T_{b}\right)}{G R_{50}}
$$

The different variables to solve this equation were obtained as follows:

Equation $2(1 / \mathrm{t}(50))$ was used to calculate $\mathrm{GR}_{50}$ for different treatments. In each treatment, the results of $G R_{50}$ were used to calculate a linear regression whose $\mathrm{x}$ intercept represented the estimated value of $\mathrm{T}_{b}[46,61]$. The $\mathrm{T}_{\mathrm{o}}$ was obtained from the relationship between different percentiles of GR (30,50 and 70\%) and the $\mathrm{T}_{\mathrm{m}}$ of each thermal regime ( $\mathrm{C}$ or $\mathrm{A})$ with the same darkness treatments where $\mathrm{T}_{\mathrm{o}}$ was the point on the $\mathrm{x}$-axis that coincided with the maximum $\mathrm{GR}_{30}, \mathrm{GR}_{50}$, and $\mathrm{GR}_{70}$ of the above relationship. The estimated $\theta_{\mathrm{T}}(50)$ was used to obtain the $\sigma$ of the log thermal time in the different treatments and using the logit model [29], the median germination time was estimated using the values to $\operatorname{logit}=0$ as was mentioned above. Only GR\% values less than $95 \%$ from $\mathrm{T}_{\mathrm{b}}$ to $\mathrm{T}_{\mathrm{o}}$ were included in the logit regression [28]

\section{Validation of thermal time model}

The evaluation process is an important part of the design of a model because it allows checking the concordance between expected and observed results. The method of evaluation used in this work is based on the coefficient of determination $\left(\mathrm{R}^{2}\right)$ and the root-meansquare error (RMSE). This method provides an estimation of the difference between $\log \left(\theta_{T}(\mathrm{~g})\right)$ obtained in each model (expected values) and $\log \left(\theta_{T}(\mathrm{~g})\right)_{\text {To }}$ (observed values), where $\log \left(\theta \mathrm{T}(\mathrm{g})_{\text {To }}\right.$ was calculated applying thermal parameters of each model (Table 4) to data germination of To population.

\section{Statistical analyses}

The multifactor analysis of variance with final germination response as a percentage was carried out with the software package Statgraphics Centurion XVI (Starpoint Technologies, 2011) to determine the relationships among origin, thermal conditions and darkness period of cattail seeds. Germination responses were transformed to meet the assumption of the ANOVA. In this case, the transformation used was arcsine $(\sqrt{\text { final }}$ germination $\%)$. A multiple range test was also performed to determine which variables were significantly different from the others. The method to make the comparisons was LSD (Least Significance Difference). Statistical differences were defined as $p<0.05$. 


\section{Availability of data and materials}

All data generated or analysed and its supplementary information files during this study are included in this published article. The datasets used and/or analyzed during the current study are available from the corresponding author on reasonable request.

\section{Supplementary information}

Supplementary information accompanies this paper at https://doi.org/10. 1186/s12870-020-02573-3.

\section{Additional file 1.}

\section{Abbreviations}

$\Delta \mathrm{T}$ : The temperature difference; $\theta_{T}(\mathrm{~g})$ : Thermal time; $\sigma \theta_{T}$ : Standard deviation of $\theta_{T}$ : A: Alternating; ANOVA: Analysis of variance; Ba: Badajoz; C: Constante; Cu: Cuenca; DT: Darkness treatments; g: the percentile of germination; GA: Agroenergy Group; GFF: Green floating filter; GR: Germination rate; IUCN: International Union for Conservation of Nature and Natural Resources; LD: light/dark; LSD: Least Significance Difference; Ma: Madrid;

PAR: Photosynthetic Active Radiation; probs: Probit transformation; Se: Seville; $T_{b}$ : Base temperature; $T_{m}$ : Mean temperature; $\left.t_{g}\right)$ : time of germination;

$T_{0}$ : Optimum temperature; To: Toledo; USA: United States of America

\section{Acknowledgments}

FMC is supported by a grant from the National Program of Scholarships and Educational Loan (PRONABEC) - Ministry of Education Peru.

\section{Authors' contributions}

FMC performed and analyzed the seed germination test. PLA interpreted and proceeded with the data analyzed. MCM and MTC review and improved the thermal time model. FMC and PLA conceived the study, planned experiments, and draft the manuscript. All authors read and approved the final manuscript

\section{Funding}

Not applicable.

\section{Availability of data and materials}

All data generated or analyzed and its supplementary information files during this study are included in this published article. The datasets used and/or analyzed during the current study are available from the corresponding author on reasonable request.

\section{Ethics approval and consent to participate}

Not applicable.

\section{Consent for publication}

Not applicable.

\section{Competing interests}

The authors declare that they have no competing interests.

\section{Author details}

${ }^{1}$ Agroenergy Research Group, Department of Agricultural Production. School of Agricultural, Food and Biosystems Engineering, Universidad Politecnica de Madrid (UPM), Avenue Complutense s/n, 28040 Madrid, Spain. ${ }^{2}$ Department of Applied Mathematics. School of Agricultural, Food and Biosystems Engineering, Universidad Politecnica de Madrid (UPM), Avenue Complutense s/n, 28040 Madrid, Spain.

Received: 8 January 2020 Accepted: 23 July 2020

Published online: 17 August 2020

\section{References}

1. CABI. Typha domingensis. In: Invasive Species Compendium; 2020. https:// www.cabi.org/isc/datasheet/54296. Accessed 15 Jan 2019.
2. Bansal S, Lishawa SC, Newman S, Tangen BA, Wilcox D, Albert D, et al Typha (cattail) invasion in north American wetlands: biology, regional problems, impacts, ecosystem services, and management. Wetlands. 2019; 39(4):645-84. https://doi.org/10.1007/s13157-019-01174-7.

3. Cirujano S. CLXXV. Typhaceae. In: Flora Iberica Plantas vasculares de la Peninsula Ibérica e Islas Baleares. Volumen 18. Real Jardin Botánico: CSIC; 2007. p. 259-66

4. Finkelstein SA. Identifying pollen grains of Typha latifolia, Typha angustifolia, and Typha $\times$ glauca. Can J Bot. 2003;81(9):985-90. https://doi.org/10.1139/ b03-084.

5. Lorenzen B, Brix H, McKee KL, Mendelssohn IA, Miao S. Seed germination of two Everglades species, Cladium jamaicense and Typha domingensis. Aquat Bot. 2000;66(3):169-80. https://doi.org/10.1016/S0304-3770(99)00076-5.

6. Osti JASS, Henares MNPP, Camargo AFMM. The efficiency of free-floating and emergent aquatic macrophytes in constructed wetlands for the treatment of a fishpond effluent. Aquac Res. 2018;49(10):3468-76. https:// doi.org/10.1111/are.13813.

7. Benvenutia T, Fernando Hamerskib AG, Andréa M, Bernardesb JZ-F, MAS R. Constructed floating wetland for the treatment of domestic sewage: a realscale study. J Environ Chem Eng. 2018;6(5):5706-11. https://doi.org/10.1016/ j.jece.2018.08.067

8. Headley TR, Tanner CC. Constructed wetlands with floating emergent macrophytes: An innovative stormwater treatment technology. Crit Rev Environ Sci Technol. 2012;42(21):2261-310. https://doi.org/10.1080/ 10643389.2011.574108.

9. Curt MD, Martín-Girela I, Martínez A, Aguado PL, Fernández J. Assessing key parameters of productivity for a non-land-dependent system of biomass production. In: 27th European Biomass Conference and Exhibition, EUBCE 2019. Lisbon; 2019. p. 207-12.

10. McNaughton SJ. R- and K-selection in Typha. Am Nat. 1975;109(967):251-61. https://doi.org/10.1086/282995.

11. Grace JB. The effects of nutrient additions on mixtures of Typha latifolia $L$. and Typha domingensis pers. along a water-depth gradient. Aquat Bot. 1988; 31(1-2):83-92. https://doi.org/10.1016/0304-3770(88)90040-X.

12. Fernández J. Patentt No.: WO/1998/045213, Patent No.: ES98/00086. 1998, and Patente No.: US 6,433,699 B1; 2001.

13. Ciria MP, Solano ML, Soriano P. Role of macrophyte Typha latifolia in a constructed wetland for wastewater treatment and assessment of its potential as a biomass fuel. Biosyst Eng. 2005;92(4):535-44. https://doi.org/ 10.1016/j.biosystemseng.2005.08.007.

14. Berry P, Yassin F, Grosshans R, Lindenschmidt KE. Surface water retention systems for cattail production as a biofuel. J Environ Manag. 2017. https:// doi.org/10.1016/j.jenvman.2017.08.019.

15. Colbers B, Cornelis S, Geraets E, Ramírez-Gaona M. A feasibility study on the usage of cattail (Typha spp.) for the production of insulation materials and bio-adhesives. Wageningen; 2017.

16. Stewart H, Miao SL, Colbert M, Carraher CE. Seed germination of two cattail (Typha) species as a function of Everglandes nutrient levels. Wetlands. 1997; 17(1):116-22. https://doi.org/10.1007/BF03160723.

17. Heinz SI. Population biology of Typha latifolia L. and Typha angustifolia L.: establishment, growth and reproduction in a constructed wetland. Technische Universität München; 2012.

18. Benech-Arnold RL, Sánchez RA, Forcella F, Kruk BC, Ghersa CM. Environmental control of dormancy in weed seed banks in soil. F Crop Res. 2000;67(2):105-22. https://doi.org/10.1016/S0378-4290(00)00087-3.

19. Batlla D, Benech-Arnold RL. A framework for the interpretation of temperature effects on dormancy and germination in seed populations showing dormancy Science Research. Seed Sci Res. 2015;25(2):147-58. https://doi.org/10.1017/S0960258514000452.

20. Finch-Savage WE, Leubner-Metzger G. Seed dormancy and the control of germination. New Phytol. 2006;171(3):501-23. https://doi.org/10.1111/j.14698137.2006.01787.x.

21. Del Monte JP, Dorado J. Effects of light conditions and after-ripening time on seed dormancy loss of Bromus diandrus Roth. Weed Res. 2011;51(6):58190. https://doi.org/10.1111/j.1365-3180.2011.00882.x.

22. Lombardi T, Fochetti T, Bertacchi A, Onnis A. Germination requirements in a population of Typha latifolia. Aquat Bot. 1997;56(1):1-10. https://doi.org/10. 1016/S0304-3770(96)01096-0.

23. Ekstam B, Forseby $\AA$. Germination response of Phragmites australis and Typha latifolia to diurnal fluctuations in temperature. Seed Sci Res. 1999;9(2): 157-63. https://doi.org/10.1017/S0960258599000173. 
24. Meng $H$, Wang $X$, Tong $S$, Lu $X$, Hao M, An Y, et al. Seed germination environments of Typha latifolia and Phragmites australis in wetland restoration. Ecol Eng. 2016;96:194-9. https://doi.org/10.1016/j.ecoleng.2016.03.003.

25. Bewley JD, Bradford KJ, Hilhorst HWM, Nonogaki H. Seeds. Physiology of development, germination and dormancy. 3rd ed. New York: Springer Science \& Business Media; 2013.

26. Bouwmeester $\mathrm{HJ}$, Karssen $\mathrm{CM}$. The dual role of temperature in the regulation of the seasonal changes in dormancy and germination of seeds of Polygonum persicaria L. Oecologia. 1992;90(1):88-94. https://doi.org/10.1007/BF00317813.

27. Del Monte JP, Tarquis AM. The role of temperature in the seed germination of two species of the Solanum nigrum complex. J Exp Bot. 1997;48(12): 2087-93. https://doi.org/10.1093/jxb/48.12.2087.

28. Bradford K, Tarquis AM, Duran JM. A population-based threshold model describing the relationship between germination rates and seed deterioration. J Exp Bot. 1993;44(7):1225-34. https://doi.org/10.1093/jxb/44.7.1225.

29. Del Monte JP, Aguado PL, Tarquis AM. Thermal time model of Solanum sarrachoides germination. Seed Sci Res. 2014;24(4):321-30. https://doi.org/10. 1017/S0960258514000221.

30. Ellis $\mathrm{RH}$, Barret $\mathrm{S}$. Alternating temperatures and rate of seed germination in lentil. Ann Bot. 1994;74(5):519-24. https://doi.org/10.1006/anbo.1994.1149.

31. Pons TL. Seeds responses to light. In: International C, editor. Seeds: The Ecology of Regeneration in Plant Communities. 2nd ed. United Kingdom; 2000. p. 237-60

32. Sánchez-García EA, Rodríguez-Medina K, Moreno-Casasola P. Effects of soil saturation and salinity on seed germination in seven freshwater marsh species from the tropical coast of the Gulf of Mexico. Aquat Bot. 2017; 140(April):4-12. https://doi.org/10.1016/j.aquabot.2017.04.002.

33. Bonnewell V, Koukkari WL, Pratt DC. Light, oxygen, and temperature requirements for Typha latifolia seed germination. Can J Bot. 1983;61(5): 1330-6. https://doi.org/10.1139/b83-140.

34. Evans CE, Etherington JR. The effect of soil water potential on seed germination of some British plants. New Phytol. 1990;115(3):539-48. https:// doi.org/10.1111/j.1469-8137.1990.tb00482.x.

35. Pendleton B, Meyer S. Habitat-correlated variation in blackbrush (Coleogyne ramosissima: Rosaceae) seed germination response. J Arid Environ. 2004; 59(2):229-43. https://doi.org/10.1016/j.jaridenv.2003.12.009.

36. Schmuths H, Bachmann K, Weber WE, Horres R, Hoffmann MH. Effects of preconditioning and temperature during germination of 73 natural accessions of Arabidopsis thaliana. Ann Bot. 2006;97(4):623-34. https://doi. org/10.1093/aob/mcl012

37. Qiu J, Bai Y, Fu Y-B, Wilmshurst JF. Spatial variation in temperature thresholds during seed germination of remnant Festuca hallii populations across the Canadian prairie. Environ Exp Bot. 2010;67(3):479-86. https://doi org/10.1016/j.envexpbot.2009.09.002.

38. Sugiyama S. Geographical distribution and phenotypic differentiation in populations of Dactylis glomerata L. in Japan. Plant Ecol. 2003;169(2):295305. https://doi.org/10.1023/A:1026081122985

39. Boers AM, Veltman RLD, Zedler JB, Consulting NR, Box PO, Street SM, et al. Typha $\times$ glauca dominance and extended hydroperiod constrain restoration of wetland diversity. Ecol Eng. 2006;9:232-44. https://doi.org/10.1016/j. ecoleng.2006.04.011.

40. Dahal P, Bradford KJ. Effects of priming and endosperm integrity on seed germination rates of tomato genotypes. J Exp Bot. 1990;41(11):1441-53. https://doi.org/10.1093/jxb/41.11.1441.

41. Forcella F, Benech Arnold RL, Sanchez R, Ghersa CM. Modeling seedling emergence. F Crop Res. 2000;67(2):123-39. https://doi.org/10.1016/S03784290(00)00088-5.

42. Bradford KJ. Applications of hydrothermal time to quantifying and modeling seed germination and dormancy. Weed Sci. 2002;50(2):248-60. https://doi.org/10.1614/0043-1745(2002)050[0248:aohttq]2.0.co;2.

43. Rowse H, Finch-Savage W. Hydrothermal threshold models can describe the germination response of carrot (Daucus carota) and onion (Allium cepa) seed populations across both sub- and supra-optimal temperatures. New Phytol. 2003;158(1):101-8. https://doi.org/10.1046/j.1469-8137.2003.00707.x.

44. Bradford KJ. A water relations analysis of seed germination rates. Plant Physiol. 1990;94(2):840-9. https://doi.org/10.1104/pp.94.2.840.

45. Garcia-Huidobro J, Monteith JL, Squire GR. Time, temperature and germination of Pearl Millet (Pennisetum typhoides S .\& H .). J Exp Bot. 1982;33(133):288-96.

46. Covell S, Ellis RH, Roberts EH, Summerfield RJ. The influence of temperature on seed germination rate in Grain Legumes. J Exp Bot. 1986;37(5):705-15. https://doi.org/10.1093/jxb/37.5.705.
47. AEMET. The State Meteorological Agency of Spain. 2019. http://www.aemet. es/es/serviciosclimaticos/datosclimatologicos. Accessed 1 Nov 2019.

48. Milberg P, Andersson L, Noronha A. Seed germination after short-duration light exposure: implications for the photo-control of weeds. J Appl Ecol. 1996;33(6):1469. https://doi.org/10.2307/2404785.

49. Baskin CC, Baskin JM. Seeds. Ecology, biogeography, and, evolution of dormancy and germination. 2nd ed: Elsevier; 2014.

50. Sifton HB. The germination of light-sensitive seeds of Typha latifolia L. Can J Bot. 1959:37(4):719-39. https://doi.org/10.1139/b59-057.

51. Kristie DN, Bassi PK, Spencer MS. Factors affecting the induction of secondary dormancy in lettuce. Plant Physiol. 1981;67(6):1224-9. https://doi. org/10.1104/pp.67.6.1224.

52. Pons TL. Induction of dark dormancy in seeds: its importance for the seed bank in the soil. Funct Ecol. 1991;5(5):669. https://doi.org/10.2307/2389487.

53. Seabloom EW, Van Der Valk AG, Moloney KA. The role of water depth and soil temperature in determining initial composition of prairie wetland coenoclines. Plant Ecol. 1998;138(2):203-16. https://doi.org/10.1023/A:1009711919757.

54. Coops $\mathrm{H}$, Velde $\mathrm{G}$. Seed dispersal, germination and seedling growth of six helophyte species in relation to water-level zonation. Freshw Biol. 1995; 34(1):13-20. https://doi.org/10.1111/j.1365-2427.1995.tb00418.x.

55. Galinato MI, Van Der Valk AG. Seed germination traits of annuals and emergents recruited during drawdowns in the Delta marsh, Manitoba, Canada. Aquat Bot. 1986;26:89-102. https://doi.org/10.1016/0304-3770(86)90007-0.

56. Nicol JM, Ganf GG. Water regimes, seedling recruitment and establishment in three wetland plant species. Mar Freshw Res. 2000;51(4):305. https://doi. org/10.1071/MF99147.

57. Mohsen MN, Mahdi B, Abolfazl T. Effect of seed size and genotype on germination characteristic and seed nutrient content of wheat. Sci Res Essays. 2011;6(9):2019-25. https://doi.org/10.5897/SRE11.621.

58. Tozzi E, Beckie H, Weiss R, Gonzalez-Andujar JL, Storkey J, Cici SZH, et al. Seed germination response to temperature for a range of international populations of Conyza canadensis. Fernandez-Quintanilla C, editor. Weed Res. 2014:54(2):178-85. https://doi.org/10.1111/wre.12065.

59. Donohue K, Dorn L, Griffith C, Kim E, Aguilera A, Polisetty CR, et al. Environmental and genetic influences on the germination of Arabidopsis thallana in the field. Evolution (N Y). 2005;59(4):740-57. https://doi.org/10. 1111/j.0014-3820.2005.tb01750.x.

60. McNaughton SJ. Ecotype function in the Typha community. Ecol Monogr. 1966;36(4):297-325. https://doi.org/10.2307/1942372.

61. Kebreab E, Murdoch AJ. A model of the effects of a wide range of constant and alternating temperatures on seed germination of four Orobanche species. Ann Bot. 1999;84(4):549-57. https://doi.org/10.1006/anbo.1998.0948.

62. Steinmaus SJ, Prather TS, Holt JS. Estimation of base temperatures for nine weed species. J Exp Bot. 2000;51(343):275-86. https://doi.org/10.1093/ jexbot/51.343.275

63. Parsons WT, Cuthbertson EG. Noxious weeds of Australia. Melbourne: Inkata Press; 1992.

64. Royal Botanic Gardens. Seed information database. 2002. http://data.kew. org/sid/SidServlet?|D=31021\&Num=dSB\#Germination. Accessed 30 Jan 2019

65. Lacey EP. Parental effects in Plantago lanceolata L. i.: a growth chamber experiment to examine pre- and postzygotic temperature effects. Evolution (N Y). 1996:50(2):865-78. https://doi.org/10.1111/j.1558-5646.1996.tb03895.x.

66. Murdoch AJ, Roberts EH, Goedert CO. A model for germination responses to alternating temperatures. Ann Bot. 1989;63(1):97-111. https://doi.org/10. 1093/oxfordjournals.aob.a087733.

67. Nakao EA, Cardoso VJM. Analysis of thermal dependence on the germination of braquiarão seeds using the thermal time model. Brazilian J Biol. 2016;76(1):162-8. https://doi.org/10.1590/1519-6984.15714.

68. Lansdown RV. The IUCN Red list of threatened species: e.T164208A120229199. International Union for Conservation of Nature and Natural Resources https:// www.iucnredlist.org/species/164208/1202291992019. Accessed 27 Jan 2019.

69. Chen SSC, Chang JLL. Does gibberellic acid stimulate seed germination via amylase synthesis? Plant Physiol. 1972;49(3):441-2. https:/doi.org/10.1104/pp.49.3.441.

70. Finney DJ. Probit Analysis. J Pharm Sci. 1971;60(9):1432. https://doi.org/10. 1002/jps.2600600940.

71. Hewlett PS, Plackett RL. An introduccion ot the interpretation of quantal responses in biology. Baltimore: University Park Press; 1979.

\section{Publisher's Note}

Springer Nature remains neutral with regard to jurisdictional claims in published maps and institutional affiliations. 